\title{
Lectin domains at the frontiers of plant defense
}

\author{
Nausicaä Lannoo and Els J. M. Van Damme* \\ Laboratory of Biochemistry and Glycobiology, Department of Molecular Biotechnology, Ghent University, Ghent, Belgium
}

\section{Edited by:}

Elisabeth Jamet, Laboratoire de Recherche en Sciences Végétales, France

\section{Reviewed by:}

Raimund Tenhaken, University of Salzburg, Austria

Thomas Sebastian Nuhse, The University of Manchester, UK

\section{${ }^{*}$ Correspondence:}

Els J. M. Van Damme, Laboratory of Biochemistry and Glycobiology, Department of Molecular

Biotechnology, Ghent University, Coupure Links 653, B-9000 Ghent Belgium

e-mail: elsjm.vandamme@ugent.be
Plants are under constant attack from pathogens and herbivorous insects. To protect and defend themselves, plants evolved a multi-layered surveillance system, known as the innate immune system. Plants sense their encounters upon perception of conserved microbial structures and damage-associated patterns using cell-surface and intracellular immune receptors. Plant lectins and proteins with one or more lectin domains represent a major part of these receptors. The whole group of plant lectins comprises an elaborate collection of proteins capable of recognizing and interacting with specific carbohydrate structures, either originating from the invading organisms or from damaged plant cell wall structures. Due to the vast diversity in protein structures, carbohydrate recognition domains and glycan binding specificities, plant lectins constitute a very diverse protein superfamily. In the last decade, new types of nucleocytoplasmic plant lectins have been identified and characterized, in particular lectins expressed inside the nucleus and the cytoplasm of plant cells often as part of a specific plant response upon exposure to different stress factors or changing environmental conditions. In this review, we provide an overview on plant lectin motifs used in the constant battle against pathogens and predators during plant defenses.

Keywords: carbohydrate, innate immunity, lectin, protein-carbohydrate interaction, PRR

\section{INTRODUCTION}

In nature, plants are constantly exposed to a plethora of different pathogens including bacteria, viruses, and fungi. Whereas the interaction with some of these organisms can be beneficial, most microbial infection is harmful for the plant (Dangl et al., 2013). In order to resist pathogen colonization, plants developed a highly sophisticated, multilayered system enabling the plant to recognize invading pathogens and mount rapidly efficient defense responses (Muthamilarasan and Prasad, 2013; Wirthmueller et al., 2013).

Microbial entry into the host tissue is a critical step in causing infection. Pathogens can enter plants through natural openings such as stomata, hydathodes, lateral roots, or through accidental wounds, but can also form specialized structures such as haustoria to penetrate directly into the plant surface (Melotto et al., 2006; Gudesblat et al., 2009). Many phytopathogens also produce lytic enzymes to damage the plant cell wall in favor of pathogen invasion. Perception of the invading pathogen is the first step in the plant's defense and is governed by cell surface transmembrane receptors. These pattern recognition receptors or PRRs are able to recognize two types of molecules.

The first group encompasses the damage-associated molecular patterns (DAMPs) which are produced in the plant apoplast as a consequence of pathogen entry. Examples include cell wall fragments such as oligogalacturonides and cellulose fragments, cutin monomers, and peptides such as systemin, defensins, and phytosulfokines (Ryan, 2000; Nühse, 2012; Albert, 2013). PRRs are also able to recognize conserved microbial structures, known as pathogen- or microbe-associated molecular patterns (PAMPs/MAMPs), which are essential for the microbial physiology and the pathogen's fitness (Newman et al., 2013; Wirthmueller et al., 2013). Examples of PAMPs/MAMPs include lipopolysaccharides (LPS) of Gram-negative bacteria, peptidoglycan (PGN) of Gram-positive bacteria, bacterial flagellins, eubacterial elongation factors (EF-Tu), and fungal cell wall derived glucans, chitins, and proteins.

Upon PAMP/MAMP and DAMP perception by the PRRs, the so-called PAMP/MAMP-triggered immunity (PTI/MTI) response is activated which gives rise to downstream intracellular signaling events such as activation of mitogen-activated protein kinases, production of reactive oxygen species and transcriptional reprogramming ultimately leading to a complex output response of the plant that limits microbial growth (Wirthmueller et al., 2013).

However, successful pathogens have elaborated a counter defense response to overcome PTI by means of expression of specific elicitors or effector proteins [also known as avirulence (Avr) proteins; Grant et al., 2006]. Pathogenic bacteria typically inject these effectors directly into the cytoplasm of the plant host cell through type III secretion mechanisms to suppress and/or block PRR-dependent signaling, to facilitate nutrient acquisition and to contribute to the pathogen's dispersal which can lead to effector-triggered susceptibility (ETS; Block et al., 2013; Cui et al., 2013).

As a counter move, plants have co-evolved a second layer of defense, known as effector-triggered immunity (ETI) which, in contrast to PTI/MTI acts mostly inside the plant cell. In ETI, specific resistance $(R)$ genes become expressed upon recognition of an effector to produce defense proteins. The majority of the $\mathrm{R}$ proteins include nucleotide-binding leucine-rich repeat (NBLRR)-containing proteins. The outcome of PTI/MTI and ETI can lead to programmed cell death of the host cell via (local) activation of a hypersensitive response (HR), but can also initiate systemic acquired resistance (SAR) to activate defenses in distal, 
non-infected parts of plants in order to establish a heightened state of immunity throughout the plant (Thomma et al., 2011).

\section{PATHOGEN RECOGNITION RECEPTORS (PRRs)}

The cell wall confers the first tier of the plant's immunity (Malinovsky et al., 2014). The extracellular PRRs are able to detect pathogen determinants (the so-called PAMPs/MAMPs), DAMPs and effectors at the surface of the plant cell and are used to translocate the extracellular message of 'danger' to the intracellular environment to trigger appropriate defense mechanisms (Figure 1A; Dubery etal., 2012). The PRR family encompasses two groups of plasma membrane-localized proteins: the receptor-like kinases (RLKs) and the receptor-like proteins (RLPs). RLKs are single-pass transmembrane proteins with an extracellular domain that is responsible for the perception of the $\mathrm{P} / \mathrm{M} / \mathrm{DAMPs}$ and an intracellular serine/threonine kinase domain that activates the downstream signaling responses. RLPs possess a similar structure but, because they only have a short cytosolic domain without an obvious signaling module, they depend on the association with kinases for signaling. However, there is emerging evidence that upon ligand binding RLKs also form homodimers or heterodimers with other kinases and RLPs and as such function in multiprotein complexes to initiate plant immunity (Boller and Felix, 2009; Böhm et al., 2014; Han et al., 2014; Macho and Zipfel, 2014).

Thus far, only a limited number of RLKs and RLPs that may function in plant immunity have been functionally characterized. Matching these proteins to their ligands is still a challenging study. The majority of the known PRR ectodomains contains LRRs for direct/indirect recognition of pathogenic effector proteins (Table 1). In addition, a large diversity of membrane-bound and soluble PRRs have been described to carry lectin domains that are implicated in the recognition of carbohydrate structures from microbial organisms or derived from plant cell wall damage (Tables 2 and 3 ).

\section{PATHOGEN RECOGNITION BASED ON PROTEIN-PROTEIN INTERACTIONS}

The study of plant-pathogen interactions has focused on those PRRs which use protein-protein interactions to recognize invading pathogens. Phytopathogens are recognized upon perception of characteristic epitopes present on their surface and essential for the pathogen's survival. These epitopes are mostly recognized by plant cell surface receptors carrying LRR motifs in their ectodomain structures and a kinase domain in their intracellular domain, collectively named the LRR-RLKs. Since these protein-protein interactions have been the subject of several recent overview papers, we only briefly summarize some plant LRR-RLKs and LRR-RLPs (Figure 1B and Table 1).

Amongst the plant PRRs of the LRR-RLK type, the Arabidopsis LRR-RLK AtFLS2 (Flagellin Sensing 2) is the best-studied protein, containing 28 extracellular LRRs. This FLS2 recognizes bacterial flagellin via perception of the conserved 22-amino acid epitope flg22. AtFLS2 directly interacts with flg22 resulting in phosphorylation of AtFLS2 and immediate dimerization with its co-receptor BAK1/SERK, another LRR-RLK. Transphosphorylation of the kinase domain of BAK1 enables conformational changes and subsequent release of phosphorylated BAK1 leading to activation of downstream MAPK defense signaling (GómezGómez et al., 2001; Chinchilla et al., 2006, 2007; Schulze et al., 2010). In the absence of PAMP recognition, BAK1 itself interacts with the pseudokinase BIR2 (also LRR-RLK-type) to prevent FLS2-BAK1 heterodimerization (Halter et al., 2014). After flg22 perception, AtFLS2 is subject to endocytosis and degradation by the E3 ubiquitin ligase PUB12/13 to prevent continuous defense signaling. Newly synthesized AtFLS2 is incorporated in the plasma membrane at later times (Smith et al., 2014). In turn, virulent Pseudomonas syringae pathovars produce effector proteins, such as AvrPto, AvrPtoB, and AvrPphB to destabilize At FLS2 and thus compromise host immunity (Block and Alfano, 2011).

The transmembrane protein AtEFR represents another Arabidopsis LRR-RLK-type receptor involved in bacterial PAMP signaling (Zipfel et al., 2006). The ectodomain of AtEFR consists of 24 LRRs and is involved in the perception of the elf18 peptide, a conserved N-terminal fragment of bacterial elongation factor Tu. Many of the signaling compounds downstream of $A t \mathrm{EFR}$ are shared with AtFLS2, and AtEFR also requires dimerization with AtBAK1 for signaling. However, the action of AtEFR is independent of flagellin perception and unlike AtFLS2, $A t \mathrm{EFR}$ requires $\mathrm{N}$-glycosylation to become functional. Indeed, a single $N$-glycan is crucial for receptor abundance and ligand recognition between the pathogen and the plant cell surface (Häweker et al., 2010).

Rice plants use the transmembrane XA21 receptor kinase to confer immunity toward a number of Xanthomonas oryzae pv oryzae (Xoo) isolates, which cause leaf blight in rice. The XA21 receptor recognizes Ax21, a sulfated 17-amino acid peptide derived from the Xoo type I secreted protein (Lee et al., 2009). Also here, the action of XA21 is tightly regulated. Without PAMP, XA21 is kept in an inactive state through binding with and autophosphorylation by the ATPase XB24. Upon binding of Ax21 to XA21, the XB24/XA21 dimer dissociates and the XA21 kinase domain is released and translocated to the cell nucleus for subsequent immune signaling (Park and Ronald, 2012). Chen et al. (2014) recently reported that XA21 can also be found in a constitutive heteromeric complex with a BAK1 ortholog, named OsSERK2, and undergoes bidirectional transphosphorylation to confer resistance to the Xanthomonas bacterium.

Tomato plants encode several cell-surface LRR-RLPs such as LeEIX1/EIX2 and Ve1 which confer resistance toward Trichoderma and race 1 strains of Verticillium pathogens, respectively (Ron and Avni, 2004; Fradin et al., 2009). The ethylene-inducing xylanase EIX is a fungal $\beta$-1-4-endoxylanase that is used by Trichoderma viride to enter tomato and tobacco plants. The epitope that is recognized by the plants to elicit defense responses constitutes five amino acids that are not involved in the enzymatic activity (Rotblat et al., 2002). Both LeEIX1/EIX2 can bind EIX, but only LeEIX2 transmits the signal to activate immune responses (Ron and Avni, 2004). The ligand of the Ve1 receptor is the Ave1 peptide, a peptide conserved in several fungi and phytopathogenic bacteria. BAK1 signaling is involved in induced defense responses for both LeEIX1 and Ve1 (Fradin et al., 2009; Bar et al., 2010). 


\section{A}

\section{PLANT ATTACK}

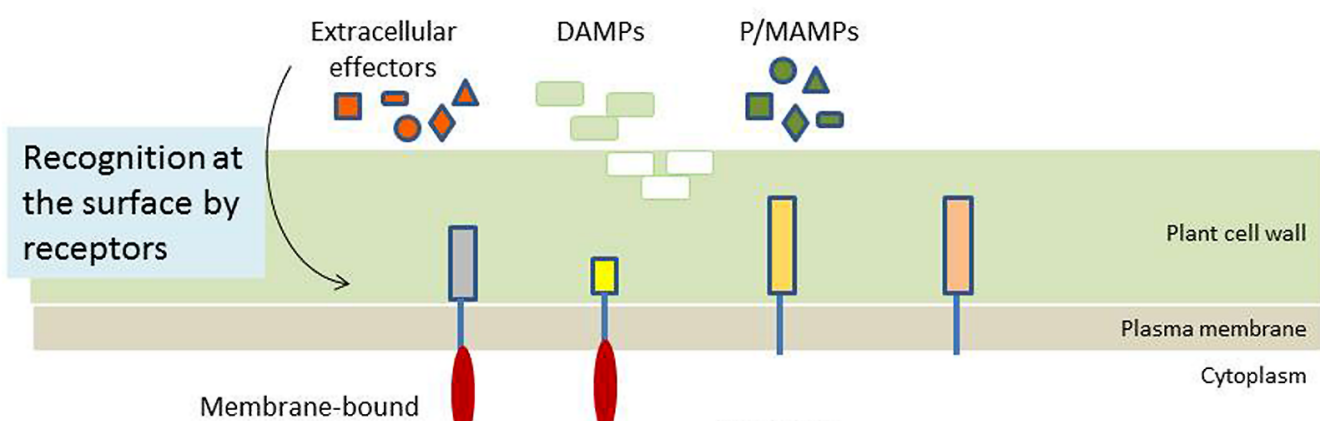
receptors:

LRR-RLKS

LecRKs

Lectin-like proteins

LRR-RLPS

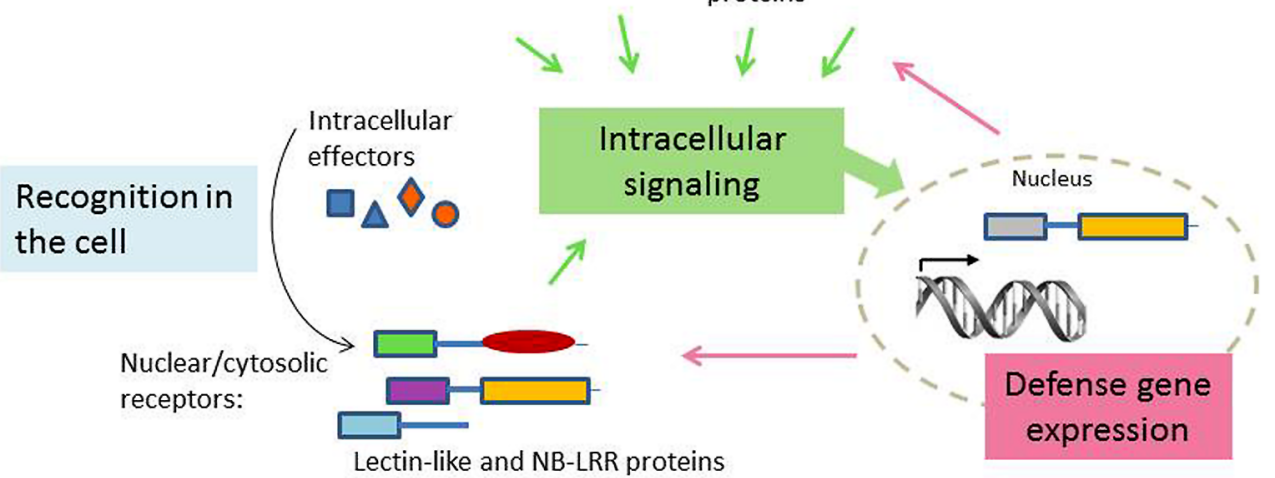

B

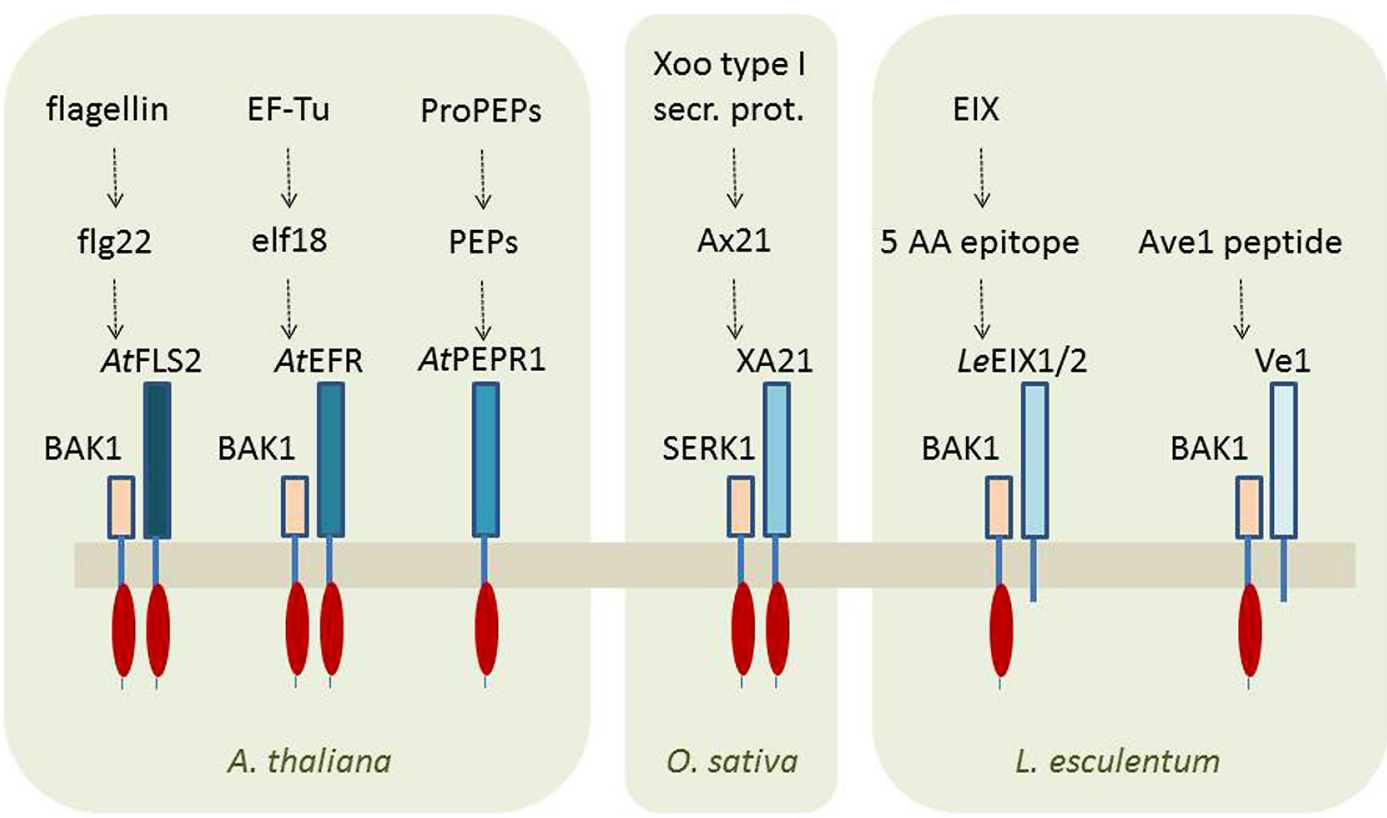

FIGURE 1 | Plant innate immunity. (A) Perception of pathogen/ microbe-associated molecular patterns (P/MAMPs), damage-associated molecular patterns (DAMPs) and pathogen-derived effector proteins. Plants sense P/MAMPs, DAMPs, and effectors through membrane-bound and intracellular (soluble) receptors. Four types of membrane-bound receptors can be distinguished: the LRR-type receptor kinases (LRR-RLKs) and proteins (LRR-RLPS), and the receptor kinases and proteins with lectin domains (called LecRKs and lectin-like proteins, respectively). Soluble receptors known thus far include NB-LRR proteins as well as nucleocytoplasmic lectins. Upon 'danger' perception, these receptors trigger intracellular signals which ultimately will result in altered expression of defense-related genes. Legend: ellipses represent kinase domains; bars represent other protein motifs, including LRRs and lectin domains. (B) Transmembrane PRRs detect P/MAMPs through protein-protein interactions. Bars represent LRR domains, red ellipses indicate functional kinase domains.

(Continued) 


\section{C}

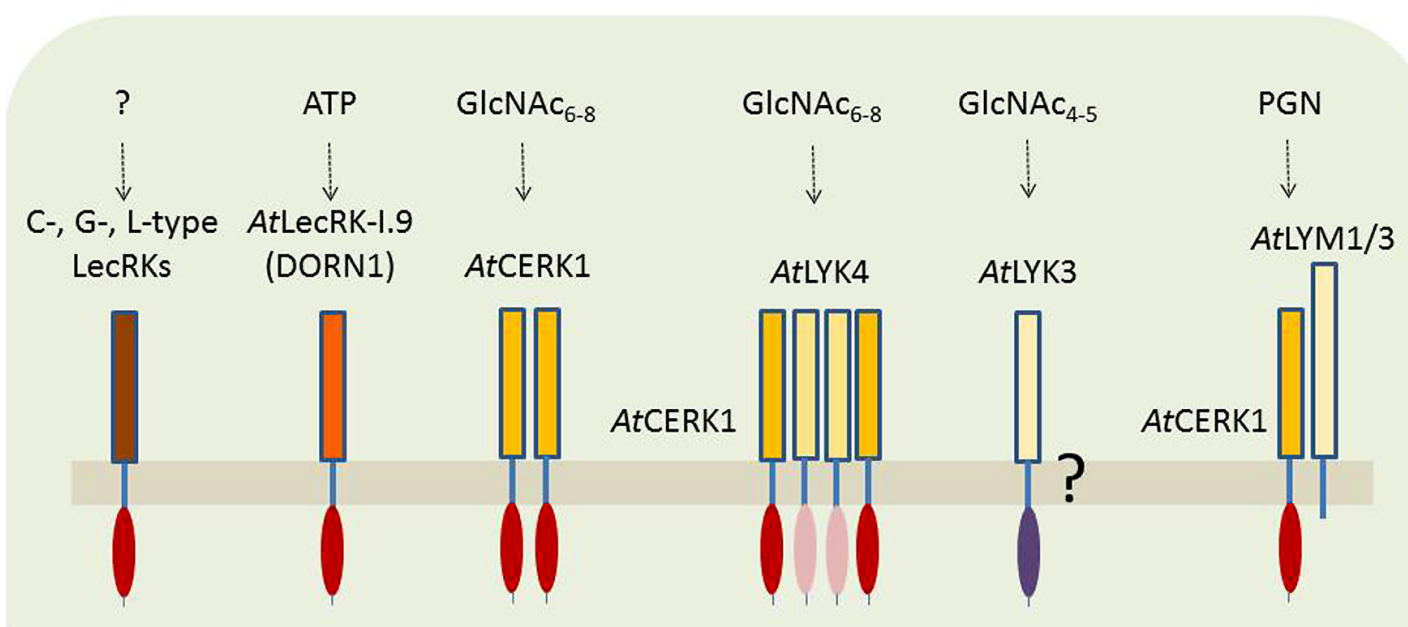

A. thaliana

D

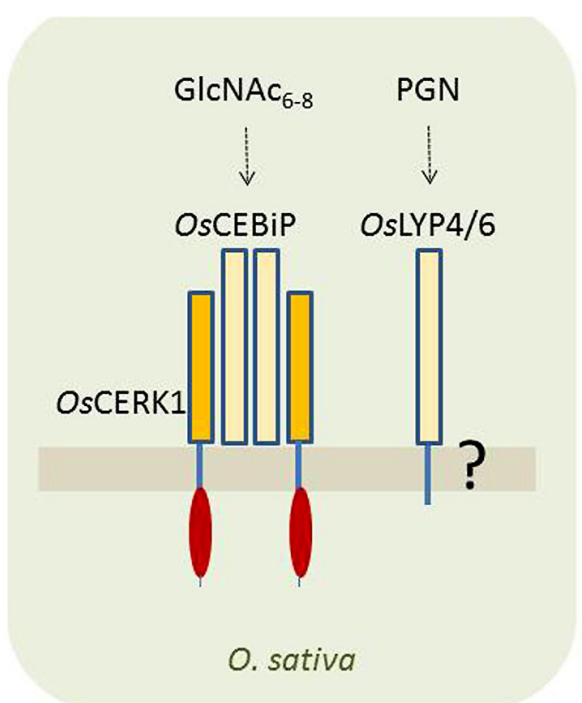

FIGURE 1 | (C) Transmembrane PRRs with lectin domains identified in Arabidopsis thaliana. In the case of the LysM domain evidence supports protein-carbohydrate interactions to detect P/M/DAMPs. Bars represent lectin domains, including C-, G-, and L-type (brown) and LysM (yellow) domains. Ellipses represent kinase domains (red = functional, pink $=$ non-functional, purple $=$ putative kinase domain). (D) Transmembrane PRRs with lectin domains identified in Oryza sativa. The LysM domain recognizes P/M/DAMPs through specific binding of chitin fragments. Bars represent the LysM lectin domains; ellipses represent functional kinase domains.

\section{PATHOGEN RECOGNITION BASED ON PROTEIN-CARBOHYDRATE INTERACTIONS THE CARBOHYDRATES}

Major part of the P/M/DAMPs that are perceived in the plant as 'danger' molecules include carbohydrate structures which are either present at the cell surface of the invading pathogen or originate from the plant itself, when released from cell wall degradation caused by pathogen entry. These structures comprise bacterial LPS and PGNs and fungal chitin molecules as well as plant-derived oligogalacturonides and cellulose fragments. Also arabinogalactan proteins residing in the plant cell wall have been reported to be involved in plant immune responses (Newman et al., 2013).

Lipopolysaccharides are large outer membrane glycoconjugates found in Gram-negative bacteria that are composed of a lipid, a core oligosaccharide and an $O$-antigen polysaccharide chain. The lipid, called lipid A, is embedded in the bacterial membrane and is linked to the core oligosaccharide by the KDO sugar (3-deoxy-D-mannose-2-octulosonate). The core sugar ends in the $O$-antigen which is composed of oligorhamnans in many phytopathogens. 
Table 1 | LRR-type PRRs involved in plant defense signaling.

\begin{tabular}{|c|c|c|c|}
\hline PRR & Plant species & Ligand & Reference \\
\hline \multicolumn{4}{|c|}{ LRR-RLK type } \\
\hline AtFLS2 & Arabidopsis thaliana & Flagellin (Flg22) & Chinchilla et al. (2006) \\
\hline AtEFR & A. thaliana & Ef-TU & Zipfel et al. (2006) \\
\hline XA21 & Oryza sativa & Activator of XA21 (Ax21) & Lee et al. (2009) \\
\hline XA3/XA26 & & Epitope derived from Xanthomonas oryzae pv oryzae & Sun et al. (2004) \\
\hline SR160 & Lycopersicon peruvianum & (pro)systemin & Scheer and Ryan (2002) \\
\hline PEPR1 & A. thaliana & PEPR1 & Krol et al. (2010) \\
\hline NORK & Medicago truncatula & $?$ & Endre etal. (2002) \\
\hline SYMRK & Lotus japonicus & $?$ & Stracke et al. (2002) \\
\hline \multicolumn{4}{|c|}{ LRR-RLP type } \\
\hline LeEIX2 & Lycopersicon esculentum & Xylanase (EIX) & Ron and Avni (2004) \\
\hline Ve1 & L. esculentum & Ave1 peptide & Fradin etal. (2009) \\
\hline
\end{tabular}

Table 2 | Membrane-bound lectin-type PRRs involved in plant defense signaling and symbiosis.

\begin{tabular}{|c|c|c|c|}
\hline PRR & Plant species & Ligand & Reference \\
\hline \multicolumn{4}{|l|}{ LysM-RLK type } \\
\hline AtCERK1 & Arabidopsis thaliana & Chitin & Miya etal. (2007), Brotman etal. (2012) \\
\hline AtLYK3 & A. thaliana & Chitin & Paparella et al. (2014) \\
\hline AtLYK4 & A. thaliana & Chitin & Wan et al. (2012) \\
\hline OsCERK1 & Oryza sativa & Chitin (when in combination with OsCEBiP) & Kaku et al. (2006) \\
\hline NFR1 & Lotus japonicus & Lipochitooligosaccharide Nod factors & Radutoiu et al. (2003) \\
\hline LYK3 & Medicago truncatula & Lipochitooligosaccharide Nod factors & Knogge and Scheel (2006) \\
\hline NFR5 & L. japonicus & Lipochitooligosaccharide Nod factors & Radutoiu et al. (2003), Madsen etal. (2003) \\
\hline SYM10 & Pisum sativum & Lipochitooligosaccharide Nod factors? & Madsen etal. (2003) \\
\hline LYK4 & M. truncatula & Lipochitooligosaccharide Nod factors & Limpens et al. (2003) \\
\hline NFP & M. truncatula & Lipochitooligosaccharide Nod factors & Mulder et al. (2006) \\
\hline \multicolumn{4}{|l|}{ LysM-RLP type } \\
\hline LYM1/AtLYP2, LYM3/AtLYP3 & A. thaliana & Peptidoglycan & Willmann etal. (2011), Tanaka etal. (2013) \\
\hline OsCEBiP & O. sativa & Chitin & Shimizu etal. (2010) \\
\hline OsLYP4, OsLYP6 & O. sativa & Chitin + Peptidoglycan & Liu et al. (2012a) \\
\hline
\end{tabular}

Table 3 | Nucleocytoplasmic lectin domains involved in plant defense signaling.

\begin{tabular}{|c|c|c|c|}
\hline Lectin domain & Carbohydrate Specificity & Subcellular localisation & Examples \\
\hline Amaranthin domain & GalNAc, T-antigen & nucleus, cytosol & Amaranthin, $\mathrm{Hfr}-2$ \\
\hline EUL domain & Galactosides, high-mannose N-glycans & nucleus, cytosol & EEA, ArathEULS3 \\
\hline Jacalin domain & Mannose-specific subgroup / galactose-specific subgroup & nucleus, cytosol / vacuole & Orysata, TaVER2, TaHfr-1,TaJA-1 \\
\hline Nictaba domain & $(\mathrm{GlcNAc})_{n}$, high-mannose $N$-glycans, complex $N$-glycans & nucleus, cytosol & Nictaba, PPL \\
\hline Ricin-B domain & Gal/GalNAc, Sia $\alpha 2,6 \mathrm{Gal} / \mathrm{GalNAc}$ & Vacuole, nucleus, cytosol & Ricin, abrin, SNA-I, SNA-V \\
\hline
\end{tabular}


Peptidoglycans are essential cell wall components of Gram-positive and Gram-negative bacteria, and comprise alternating $\beta(1-4)$ linked $N$-acetylmuramic acid (MurNAc) and $N$-acetylglucosamine (GlcNAc) residues, with a short peptide chain attached to MurNAc.

Chitin is a long-chain polymer of $\beta(1-4)$ linked GlcNAc residues and is the main component of the fungal cell wall and the exoskeleton of insects. In case of fungi, chitin is cross-linked to $\beta$-glucan.

Oligogalacturonides are oligomers of $\alpha(1,4)$ linked galacturonosyl residues that are released from plant cell walls upon partial degradation of homogalacturonan (i.e., the major component of pectin) by pathogen attack and also upon mechanical damage.

Cellulose is an important component of the plant cell wall, built up of hundreds of $\beta(1-4)$ linked glucose residues which form long polymer chains. These chains are packed into microfibrils which give strength and flexibility to the plant cell wall.

Arabinogalactan proteins are a distinct class of complex, extensively glycosylated hydroxyproline-rich proteins (the so-called proteoglycans), widely distributed among plant species. They consist of a rather small core protein backbone which is $O$-glycosylated by type II arabinogalactan glycans and often contain an N-terminal GPI anchor. AGPs are located near the cell surface, including the plasma membrane, the apoplast, the cell wall, and the intercellular matrix, and have been implicated in many aspects of plant growth and development, such as cell expansion, proliferation, and differentiation. These AGPs are not only involved in establishing a connection between the cell wall and the plasma membrane, but would also extend to the cytoplasm, establishing a continuum between intracellular and extracellular compartments.

\section{LECTIN DOMAINS INVOLVED IN PLANT IMMUNITY}

Lectins are proteins that contain at least one non-catalytic domain which enables them to selectively recognize and bind in a reversible way to specific glycans that are either present in a free form or are part of glycoproteins and glycolipids. Plants express a huge number of highly diverse lectins, exhibiting different molecular structures and binding specificities toward endogenous (plant) glycans as well as to glycans from exogenous (non-plant) origin (Van Damme et al., 2008, 2011).

A lot of plant lectins are constitutively expressed in high amounts in seeds and vegetative storage tissues where they have been shown to play a role in plant defense (Peumans and Van Damme, 1995). In addition, plants also express minute amounts of specific lectins as particular responses toward environmental stresses and pathogen attack. In the absence of plant stress, the inducible lectins are not expressed at detectable levels. Most of the constitutively expressed lectins are synthesized with a signal peptide, and are sequestered in the vacuole or secreted to the extracellular space. In contrast, most of the inducible plant lectins reside in the nucleus and the cytoplasm of a plant cell (Lannoo and Van Damme, 2010).

The majority of the known plant lectins are built up of one or more lectin-like domains coupled to un-related domains such as aerolysin, AIG1, chitinase, dirigent, F-box, Kelch, kinase, LRR, NB-ARC, PAG, or TIR domains (Van Damme et al., 2008). Up till now, most attention of the scientific community dealing with plant innate immunity has been given to transmembrane receptor proteins containing one or more ectopic lectin domains coupled to an intracellular kinase domain. Amongst these lectin receptor kinases (LecRKs), those comprising LysM-type lectin domains are the most studied ones (Table 2; Singh and Zimmerli, 2013). However, plants use a broad variety of lectin domains to counteract pathogen attack (Table 3 ).

\section{Membrane-bound proteins with a lectin domain}

Lectin receptor kinases (LecRKs). Typically, LecRKs are twodomain proteins composed of an N-terminal extracellular lectin domain and a C-terminal cytosolic Ser/Thr kinase domain, separated by a transmembrane region (Figure 1C). Based on their lectin domain LecRKs are classified into 4 types; G-, C-, L-, and LysM-type (Singh and Zimmerli, 2013; Vaid et al., 2013). Although these LecRKs consist of at least one domain that shows striking sequence similarity with a lectin motif, very little information is available with respect to the ability of this domain to recognize and interact with specific carbohydrate structures.

G-type LecRKs contain an extracellular lectin domain which resembles the Galanthus nivalis agglutinin (GNA). However, it remains to be shown whether this sugar binding domain is indeed involved in ligand binding. Based on genome-wide analyses, 32 G-type LecRKs have been identified in Arabidopsis thaliana and 100 G-type LecRKs in rice (Vaid etal., 2012). G-type LecRKs function in self-incompatibility reactions in flowering plants (the so-called SRKs) and in plant defense to biotic stress as well as to abiotic stress (Sherman-Broyles et al., 2007; Kim et al., 2009; Sun et al., 2013).

C-type (calcium-dependent) LecRKs are mostly found in mammalian proteins that mediate immune responses and play a role in pathogen recognition. In plants, C-type RLKs are rather rare. At present only one C-type LecRK encoding gene has been identified in A. thaliana (At1g52310), though its function has not been elucidated yet (Cambi et al., 2005; Bouwmeester and Govers, 2009).

L-type (legume-like) LecRKs represent a more abundant group of LecRKs. Thus far, 45 L-type LecRKs have been identified in A. thaliana. Based on phylogenetic relationships the genes encoding Arabidopsis L-type LecRK can be classified into nine clusters and nine clades (designated with the Roman numerals I to IX). These genes showed variable expression patterns in different tissues and developmental stages in response to stimuli (Bouwmeester and Govers, 2009). Some LecRKs were indeed reported to be involved in plant resistance to pathogens, e.g., AtLecRK-I.9 is involved in sensing cell wall integrity and defense response to Phytophthora infestans (Bouwmeester et al., 2011). AtLecRK-VI.2 is critical for resistance against Pseudomonas syringae and Pectobacterium carotovorum (Singh et al., 2012; Huang et al., 2014) while AtLecRK-IV.3 induces resistance against Botrytis cinerea (Huang etal., 2013). Some AtLecRKs have also been reported to act in hormone signaling (ABA) and stomatal immunity (e.g., AtLecRK-VI.2 and AtLecRK-V.5; Singh et al., 2012). L-type LecRKs have also been identified in other plants. For instance, tobacco plants express L-type LecRKs 
with a role in plant immunity against pathogens and insects (Kanzaki et al., 2008; Gilardoni et al., 2011). In turn, Medicago plants contain L-type LecRKs that are involved in symbiosis (Navarro-Gochicoa et al., 2003).

At present, it is not yet clear whether the L-type LecRKs possess lectin activity since the amino acids important for interaction of the legume lectin domain with its specific carbohydrate ligand are poorly conserved. In contrast the hydrophobic site present in the legume-type lectin domain is preserved, suggesting that LecRKs may act in the recognition of small hydrophobic ligands (Huang et al., 2013; Choi et al., 2014). Recently, evidence was obtained that the plasma membrane localized DORN1, encoded by the AtLecRKI.9 gene, plays an important role as a receptor for extracellular ATP (Figure 1C; Choi et al., 2014). DORN1 lacks the conserved $\mathrm{Ca}^{2+}$ and $\mathrm{Mn}^{2+}$ binding residues that are critical for carbohydrate binding activity of legume lectins. Early studies also suggested the ability of the legume lectin domain to bind adenine, a component of ATP (Roberts and Goldstein, 1983). However, since adenine was unable to compete with ATP for binding to DORN1, the exact ATP binding site in DORN1 remains to be determined. These data are in good agreement with the fact that extracellular ATP is now perceived as a central signaling molecule in plant stress responses (Cao et al., 2014; Choi et al., 2014).

LysM LecRKs are the most studied LecRKs (Figures 1C,D and Table 2). They contain ectopic lysin motifs, referred to as LysM domains, which are considered to mediate binding to various types of bacterial PGN and fungal chitin, upon recognition of the GlcNAc moieties (Buist et al., 2008; Gust et al., 2012). The lysine motif, approximately 40 amino acids in length, is a ubiquitous protein domain found in most living organisms except the Archaea. It can be used as a single domain, but is also present in the form of two or occasionally three repeats in a large number of proteins. In most cases LysM motifs are coupled to other protein domains exhibiting some enzymatic activity, such as GlcNAc modification in the case of microbial hydrolases or intracellular signaling for plant kinases.

The Arabidopsis chitin elicitor receptor kinase 1 (AtCERK1, also known as LYK1/RLK1) is the major chitin receptor found in $A$. thaliana (Miya et al., 2007; Petutschnig et al., 2010; Tanaka et al., 2013). It is a membrane-anchored protein with an extracellular domain containing three LysM motifs coupled to an intracellular kinase domain. This kinase domain contains a canonical RD (Arginine-Aspartate) motif in its catalytic loop and possesses autophosphorylation activity, unlike the non-RD kinase domain of typical PRRs. AtCERK1 was reported to be involved in fungal resistance. The protein directly binds to fungal chitooligosaccharides $\left(\right.$ GlcNAc $_{n}$ with $n>2$ ) through its LysM domains, but only longer oligomers $(n>4)$ trigger immune responses. Liu et al. (2012b) demonstrated that binding of chitin oligomers $(n=8)$ to AtCERK1 induces homodimerization of the receptor, which is essential for the activation of downstream intracellular signaling, most likely by phosphorylation of both CERK1 cytoplasmic kinase domains.

AtCERK1 can also mediate perception of PGN when part of a complex with AtLYM1 and AtLYM3, two other transmembrane LysM containing proteins lacking an intracellular kinase domain (the so-called LYP proteins; Willmann et al., 2011). Next to AtCERK1 A. thaliana contains four additional LysM RLKs, designated AtLYK2-5. Since AtLYK4 and AtLYK5 can also recognize and bind to chitin molecules but have a non-functional pseudokinase domain it has been suggested they should form a complex with AtCERK1 to compose a functional chitin receptor (Wan et al., 2012). AtLYK3 possesses a functional kinase domain, but was suggested be involved in ABA signaling rather than in chitin recognition (Paparella et al., 2014).

Unlike AtCERK1, the rice ortholog OsCERK1 cannot bind directly to chitooligosaccharides. OsCERK1, a LysM LecRK with a single extracellular LysM domain, requires heterodimerization with its co-receptor OsCEBiP (chitin elicitor binding protein) for chitin binding and subsequent activation of innate immunity (Figure 1D). OsCEBiP is a transmembrane LysM receptor protein containing three LysM domains and lacking a kinase domain, resembling the Arabidopsis proteins AtLYM1 and AtLYM3. However, whereas AtLYM1 and AtLYM3 are involved in PGN binding through receptor formation with AtCERK1, OsCEBiP seems to play a major role in fungal chitin perception. Upon binding to the fungal $\mathrm{GlcNAc}_{6-8}$ oligomers, OsCEBiP homo-dimerizes at the plasma membrane of the plant cell. After this ligand-induced dimerization, the OsCEBiP sandwich-like structure forms a heteromeric complex with two OsCERK1 proteins, to activate intracellular defenses, including ROS signaling, callose deposition, and defense gene expression (Shimizu et al., 2010; Shinya et al., 2012; Hayafune et al., 2014; Kouzai et al., 2014). OsLYP4 and OsLYP6 are two additional rice LysM proteins lacking a kinase domain which presumably mediate perception of both PGN and chitin, but their action and transmembrane signal transfer remain unclear (Liu et al., 2012a).

Plants not only use LysM LecRKs to recognize pathogenic organisms, they also use them to perceive beneficial organisms such as mycorrhizal fungi and rhizobacteria implicating a dual role of LysM in both innate immunity and symbiosis (Table 2; Gust et al., 2012). Examples include the Lotus japonicus NRF1 and NRF5 (Radutoiu et al., 2003) and the Medicago truncatula LYK3 and LYK4 (Knogge and Scheel, 2006) which can recognize rhizobial lipochitin-oligosaccharide signals or Nod factors.

\section{Soluble proteins with a lectin domain}

An overview of soluble proteins with a lectin domain involved in plant defense signaling is given in Table 3.

Amaranthins. The Amaranthin family groups all proteins related to amaranthin, a lectin present in the seeds of Amaranthus caudatus. Native amaranthin is a homodimeric protein built of two $33 \mathrm{kDa}$ subunits, each comprising two tandem-arrayed homologous amaranthin domains. Amaranthin specifically recognizes the T-antigen disaccharide $\mathrm{Gal} \beta(1,3)$ GalNAc but also interacts with GalNAc. Interestingly, the amaranthin domain itself possesses no sugar binding site(s), but the specific head-to-tail arrangement of two amaranthin subunits is necessary to establish the T-antigen disaccharide binding site (Van Damme et al., 2008). Up till now, only amaranthins originating from Amaranthus species have been purified and biochemically characterized. This nucleocytoplasmic lectin was reported to enhance the plant's resistance against aphids 
when ectopically expressed in transgenic tobacco, potato, and cotton by affecting growth and development of the invading aphids (Wu et al., 2006; Xin et al., 2011).

Screening of the publicly available genome databases revealed that the amaranthin domain is widespread throughout the plant kingdom. Several chimeric proteins containing N-terminal amaranthin domain(s) coupled to unrelated protein domains have been identified (Van Damme etal., 2011). Columbine plants (Aquilegia formosa $\times$ Aquilegia pubescens) encode a protein in which two amaranthin domains are coupled to a kinase domain. Since this protein does not have a transmembrane domain, it is suggested to reside inside the cell. Cucumber, maize, and wheat plants were found to contain genes that encode proteins with amaranthin domain(s) coupled to an aerolysin domain. Aerolysins are cytolytic toxins that are mostly produced by the bacterium Aeromonas and can kill host cells upon pore formation in the plasma membrane (Degiacomi et al., 2013). In wheat, a chimeric protein called Hfr2 (Hessian fly responsive-2) is up-regulated in the leaf sheaths after feeding of virulent Hessian fly larvae and armyworms, and enhances wheat tolerance against Hessian fly larvae (Puthoff et al., 2005).

Calreticulin/calnexin. Calreticulin (CRT) and calnexin (CNX) are glucose binding lectins residing in the endoplasmic reticulum (ER) of eukaryotic cells. Both CRT and CNX act as molecular chaperones and are essential ER components ensuring proper folding and quality control of newly synthesized secretory and membrane-bound glycoproteins before ER release (Ellgaard and Frickel, 2003; Kapoor et al., 2004; Williams, 2006). While CNX is a type-I integral membrane protein, CRT is a soluble protein. Both CRT and CNX act together with their co-chaperones ERp57 and PDI, two soluble thiol-disulfide oxidoreductases. Whereas the classical chaperones associate with the peptide moiety of their substrates, CNX and CRT bind to their glycoprotein substrates primarily through specific recognition and binding to the oligosaccharide intermediates Glc $_{1} \mathrm{Man}_{7-9} \mathrm{GlcNAc}_{2}$ present on nascent glycoproteins.

In the ER quality control system, a growing polypeptide initially gets $\mathrm{N}$-glycosylated with the core glycan $\mathrm{Glc}_{3} \mathrm{Man}_{9} \mathrm{GlcNAc}_{2}$. By successive action of glucosidase I and II, the outer glucoses are trimmed resulting in a monoglucosylated glycoprotein which then serves as the substrate of CNX/CRT for proper folding. Once the glycoprotein is correctly folded, the terminal glucose of its oligosaccharide is cleaved by glucosidase II and the glycoprotein is released from the CNX/CRT/ERp57 complex for further processing. If the glycoprotein is not correctly folded, it is recognized by the UDP-glucose:glycoprotein glucosyltransferase enzyme, which acts as a folding sensor, and gets re-glucosylated to promote its renewed association with CNX/CRT. As such, de- and re-glucosylation of glycoproteins facilitates their correct folding. When folding ultimately fails, the misfolded glycoproteins are sorted out of the ER and are degraded by the proteasome, a system known as ER associated degradation or ERAD. Under adverse environmental conditions, the demand for protein folding exceeds the capacity of the system resulting in the accumulation of misfolded proteins in the
ER, giving rise to so-called ER stress (Howell, 2013; Liu and Li, 2014).

The correct folding of membrane-bound PRRs is a critical step in plant immunity. The ER quality control system not only regulates the abundance and quality of transmembrane receptors, it also affects downstream signaling of the receptor (Tintor and Saijo, 2014). The LRR-RLKs AtEFR and AtFLS2 from A. thaliana as well as the LysM LecRK NFP from $M$. truncatula require proper $N$-glycosylation for accurate functioning. Nevertheless, AtEFR and AtFLS2 production are coordinated by different ER components (Li et al., 2009; Häweker et al., 2010). Arabidopsis plants contain two types of CRTs: CRT1/2 and CRT3 isoforms (Thelin et al., 2011). Whereas CRT1 is a key chaperone in plant ER stress, CRT3 is typically involved in the quality control of AtEFR and the brassinosteroid receptor BRI1, but is not essential for AtFLS2 biogenesis (Jin et al., 2009). CRT2 appears to have a dual regulatory role in plant defense against the biotrophic pathogen $P$. syringae pv tomato DC3000 (Qiu et al., 2012). Upon pathogen invasion, CRT2 is involved in the up-regulation of SA-dependent immune signaling through its $\mathrm{Ca}^{2+}$ buffering capacity. However, CRT2 negatively influences these SA-dependent responses through its chaperone activity, resulting in the overall suppression of plant resistance toward P. syringae pv tomato DC3000.

EUL-related lectins. The family of EUL-related lectins groups all nucleocytoplasmic proteins that comprise at least one Euonymus lectin (EUL) domain. The prototype of this family is the socalled Euonymus europaeus agglutinin (EEA) which is present at very high concentrations in the arillus tissue of the spindle tree (E. europaeus). EEA is a non-glycosylated homodimeric protein composed of $17 \mathrm{kDa}$ subunits, and recognizes two structurally different classes of glycans. Glycans with carbohydrate epitopes containing galactose, such as Gal $\alpha 1-3 \mathrm{Gal}$ and Gal $\alpha 1-$ 3 Gal $\beta 1-4$ GlcNAc, blood group B [Gal $\alpha 1-3$ (Fuc $\alpha 1-2)$ Gal-], and O (Fuc $\alpha 1-2$ Gal-) epitopes are bound with a higher affinity compared to high-mannose $N$-glycans. Based on inhibition studies, it was suggested that the EUL domain might contain two different binding sites (Fouquaert et al., 2008).

Sequences with an EUL domain are present in almost all sequenced plant genomes from Embryophyta, ranging from liverworts to flowering plants. The sequence of the EUL domain is well conserved suggesting that the corresponding EUL proteins fulfill an essential role in plants. Based on the overall protein domain architecture, the EUL family can be divided into two groups containing proteins either composed of a single EUL domain (S-type EUL proteins) or of two tandemly arrayed EUL domains separated by a spacer sequence (D-type EUL proteins; Fouquaert and Van Damme, 2012). The majority of the EUL sequences encode chimeric proteins, in which the EUL domain is linked to other unknown domains. Whereas most dicot species encode one or two EUL S-type proteins, monocot, and lower plant species contain a whole set of S- and D-type EUL sequences.

In contrast to EEA, which is expressed at high concentrations in the arilli of spindle tree seeds, the EUL proteins from Oryza sativa and $A$. thaliana are very low abundant proteins. In both plants the amount of EUL transcripts is enhanced after the plant 
was subjected to different abiotic (such as dehydration, salinity, osmotic stress, and ABA treatment) and biotic (such as bacterial and fungal infection) stresses (Fouquaert and Van Damme, 2012; Al Atalah et al., 2014a).

Next to the differential regulation of gene expression, the EUL proteins show different carbohydrate binding properties. ArathEULS3 from A. thaliana preferentially interacts with $N$-glycans containing galactosylated structures such as Lewis $\mathrm{X}$ [Gal $\beta 1-4$ (Fuc $\alpha 1-3)$ GlcNAc], Lewis Y [Fuc $\alpha 1-2$ Gal $\beta 1-4$ (Fuc $\alpha 1-$ 3)GlcNAc] and lactosamine (Gal $\beta 1-4 \mathrm{GlcNAc}$ ) motifs (Van Hove et al., 2011). Similarly, both EUL domains composing the twodomain EUL protein from rice, OrysaEULD1A, show carbohydrate specificity toward galactose containing glycans (Al Atalah et al., 2014b). In contrast, the rice protein OrysaEULS2 preferably binds mannosylated N-glycan structures (Al Atalah et al., 2012). All these EUL proteins are located in the nucleus and the cytoplasm of the plant cell. In search for interacting proteins, $\mathrm{Li}$ et al. (2014) recently reported that ArathEULS3 interacts with the nuclear/cytosolic ABA receptor RCAR1. Furthermore, Berendzen et al. (2012) demonstrated interaction of ArathEULS3 with CPK3, $\mathrm{a} \mathrm{Ca}^{2+}$ dependent kinase involved in the ABA response in guard cells, supporting a role for ArathEULS3 in ABA signaling and stomatal closure.

Jacalin-related lectins (JRL). The family of jacalin-related lectins is named after jacalin, a $18 \mathrm{kDa}$ T-antigen disaccharide-binding lectin domain first isolated from the seeds of jackfruit (Artocarpus integrifolia). Based on differences in molecular structure, subcellular localization, and carbohydrate binding properties, the large group of jacalins can be subdivided into two subgroups, further referred to as the galactose binding and mannose binding JRLs, residing in the vacuolar and nucleocytoplasmic compartment of the plant cell, respectively.

Galactose-specific JRLs have been reported mainly within the family Moraceae, whereas the mannose-specific JRLs are widespread in Viridiplantae. Furthermore, recent studies have shown that the jacalin domain is not restricted to plant proteins, since a similar domain has been reported in eukaryotes outside the plant kingdom as well as in some prokaryotes (Van Damme et al., 2008; Kanagawa et al., 2014). In plants, chimeric proteins comprising one or more jacalin domains linked to an unrelated domain are widely distributed. For instance, in A. thaliana, sequences composed of one or two jacalin domains C-terminally linked to five in tandem arranged Kelch domains are present. In addition, multiple Arabidopsis genes encode a putative F-box protein with a C-terminal jacalin domain (Nagano et al., 2008). Several Poaceae species (wheat, rice, maize) express proteins consisting of an N-terminal dirigent domain (also called disease-response domain) C-terminally fused to a jacalin domain. In rice, additional types of chimerolectins were identified, either composed of an N-terminal tyrosine kinase domain coupled to two or three jacalin domains or an N-terminal NB-ARC motif coupled to a LRR and a C-terminal jacalin domain (Van Damme et al., 2008).

Many jacalin-related lectin genes have been shown to be associated with disease resistance, abiotic stress signaling, wounding, insect damage or multiple stresses (Song et al., 2014). Especially the jacalin proteins with a dirigent domain are functionally involved in plant defense. To our knowledge, these chimeric proteins have only been reported in Poaceae species. In wheat, nearly half of the jacalin-related lectin genes encode dirigent domain-containing jacalin-related proteins. Several of these proteins have been studied in some detail, amongst them TaVER2, TaHfr-1, and TaJA-1 (Song et al., 2014). Interestingly all these mannose binding lectins are expressed as a response toward plant stress. TaVER2 is specifically expressed during vernalization in wheat (Yong et al., 2003) but is also up-regulated upon jasmonate and ABA treatment (Feng et al., 2009). TaHfr-1 is up-regulated after herbivory of Hessian fly larvae (Williams et al., 2002) and TaJA-1 is specifically accumulating after jasmonate treatment (Ma et al., 2013). The mannose specific TaHfr-1 was shown to effectively inhibit Hessian fly larval feeding resulting in the delay of larval development and premature death of the pest insects (Subramanyam et al., 2008). Transgenic tobacco plants overexpressing Ta-JA1 revealed increased resistance to bacterial, fungal, and viral pathogens (Ma et al., 2010). TaVER2 homologs have been found in maize and sorghum ( $\beta$-glucosidase aggregating factor) and in rice (OsJAC1; Esen and Blanchard, 2000; Jiang et al., 2006; Kittur et al., 2009). Transgenic rice plants overexpressing OsJAC1 indicated the importance of OsJAC1 for rice growth and development (Jiang et al., 2007).

Similar to the chimerolectins also jacalin-related proteins composed only of jacalin domains are up-regulated in plant tissues subjected to certain stress treatments. For instance, Orysata was first reported as a salt inducible mannose binding lectin in the leaves of O. sativa (Zhang et al., 2000). Later it was shown that Orysata is also expressed upon JA and ABA treatment, after infection with an incompatible Magnaporthe grisea strain as well as during senescence (Lee etal., 2001; de Souza Filho et al., 2003; Qin et al., 2003). Glycan array analyses revealed that Orysata preferentially interacts with high-mannose and some more complex $N$-glycans (Al Atalah et al., 2011). In recent years, several orthologs of Orysata have been identified in Gramineae species but also in other plants, such as Helianthus tuberosus and Ipomoea batatas. The mannose specific wheat protein TaJRLL1 consisting of two jacalin-like domains is considered a component of SA and JA dependent plant defense signaling mechanisms and is activated upon fungal infection (Fusarium graminearum and Blumeria graminis; Xiang etal., 2011). However, not all jacalin-related defense proteins depend on hormone signaling. For example, the Arabidopsis jacalin-related JAX1 confers broad but specific resistance to potex viruses by inhibition of viral RNA accumulation, independent of hormone signaling (Yamaji etal., 2012). Other Arabidopsis jacalin-related proteins interact with proteins of ER bodies, i.e., ER-derived organelles presumably involved in defense against herbivores and/or pathogens (Nagano et al., 2008). Recently, the jacalin-related protein from sunflower seedlings named Helja was reported as a lectin with antifungal properties toward some pathogenic fungi of the genus Candida. Helja induces morphological changes as well as ROS production in yeast cells. Furthermore, lectin treatment also altered the membrane permeability of the cells (Regente etal., 2014). 
Nictaba-related lectins. The family of Nictaba-related lectins was named after the Nicotiana tabacum agglutinin, abbreviated as Nictaba, a $19 \mathrm{kDa}$ lectin domain originally discovered in tobacco leaves (Chen et al., 2002a) after jasmonate treatment. Though the lectin was first reported as a chito-oligosaccharide binding protein, glycan array analyses revealed that Nictaba also reacts with the inner core structure $(\mathrm{Man})_{3} \beta 1-4 \mathrm{GlcNAc} \beta 1-4 \mathrm{GlcNAc} \beta-\mathrm{N}$-Asn of high-mannose and complex $N$-glycans. Biochemical assays confirmed that Nictaba can interact in a sugar-inhibitable way with many $\mathrm{N}$-glycosylated proteins (Lannoo et al., 2006, 2007). A nuclear proteomics approach revealed the interaction of Nictaba with the core histone proteins $\mathrm{H} 2 \mathrm{~A}, \mathrm{H} 2 \mathrm{~B}$, and $\mathrm{H} 4$ through their O-GlcNAc modification (Schouppe et al., 2011), which was later confirmed at the microscopical level (Delporte et al., 2014a).

An extensive survey of the genome/transcriptome databases indicated that Nictaba-like domains are widespread among the Embryophyta but are absent from other eukaryotes and prokaryotes. Few proteins belonging to the Nictaba-like family consist of a single Nictaba domain. Furthermore, numerous sequences were identified encoding chimeric proteins comprising the Nictaba domain fused to unrelated N-terminal domains (e.g., F-box domain) or a Nictaba domain C-terminally fused to an N-terminal TIR (toll/interleukin-1 receptor) domain (found in Arabidopsis and tomato), an AIG1 (avrRpt2-induced gene) domain (identified in Arabidopsis) or a kinase domain (found in rice; Delporte et al., 2014b).

At present, only few Nictaba-related proteins have been studied for their biological properties and physiological role. A comparative analysis of the carbohydrate binding properties of Nictaba from N. tabacum, the Cucurbitaceae phloem lectin PPL, the A. thaliana homolog PP2-A1 and the A. thaliana F-box-Nictaba protein encoded by the gene At2g02360 revealed that despite the sequence similarity and the presence of conserved amino acids in the carbohydrate binding site, different Nictaba domains can interact with different glycan motifs (Delporte et al., 2014b), suggesting different biological roles.

Since insect herbivory by Lepidopteran insects also triggers the JA pathway the tobacco lectin also accumulates after caterpillar attack. Furthermore, feeding assays with (transgenic) tobacco lines demonstrated the entomotoxic activity of Nictaba. It was suggested that the entomotoxic effect of Nictaba is caused by interaction of the lectin with glycoconjugates present in the digestive tract of the insect (Vandenborre et al., 2010, 2011). Within the plant cell, insect herbivory results in enhanced Nictaba expression in the cytoplasm, followed by partial translocation of the lectin to the nucleus, where it can interact with core histone proteins through their $O$-GlcNAc modification. It is hypothesized that Nictaba binding to chromatin results in enhanced transcription of defense related genes (Lannoo and Van Damme, 2010).

The Cucurbitaceae phloem lectins are a group of Nictabarelated lectins that are found in phloem exudates of different Cucurbitaceae species. Unlike Nictaba, the PP2 lectins are exclusively and continuously expressed in the companion cells of the phloem and then translocated into the phloem sap. The pumpkin lectin PPL and the PP2-like protein from A. thaliana, PP2-A1, show high binding affinity for chitin oligomers $\left(\mathrm{GlcNAc}_{3-6}\right)$. Similar to Nictaba, PP2-A1 also binds with the $\mathrm{Man}_{3} \mathrm{GlcNAc}_{2}$ core of high-mannose $N$-glycans (Beneteau et al., 2010). Interestingly, the expression of PP2-A1 was enhanced by ethylene treatment and Pseudomonas infection. Furthermore, PP2-A1 represses phloem feeding of the green peach aphid Myzus persicae (Zhang et al., 2011), displayed antifungal activity against various fungal strains (Lee et al., 2014), and negatively affects Cucurbit aphid borne yellow virus transmission (Bencharki et al., 2010), strongly supporting a role in plant defense.

Several F-box Nictaba proteins are encoded in the A. thaliana genome. Glycan array analyses revealed the F-box protein encoded by At2g02360 exhibits carbohydrate binding activity toward $\mathrm{N}$ - and $\mathrm{O}$-glycans with $\mathrm{N}$-acetyllactosamine (LacNAc; GalB1-3GlcNAc and GalB1-4GlcNAc) and poly-LacNAc structures as well as with Lewis A (Galß1-3(Fuc $\alpha 1-4)$ GlcNAc), Lewis X (Gal $\beta 1-4$ (Fuca1-3)GlcNAc), Lewis Y (Fuc $\alpha 1-2$ Gal $\beta 1-4$ (Fuc $\alpha 1-$ 3)GlcNAc), and type-1 B motifs (Gal $\alpha 1-3$ (Fuc $\alpha 1-2)$ Gal $\beta 1-$ 3GlcNAc. Since these glycan structures have been reported in bacteria, viruses, and animals rather than in plants the physiological importance of this glycan interaction remains enigmatic (Lannoo et al., 2008; Stefanowicz et al., 2012). Furthermore, the same Arabidopsis F-box Nictaba protein was shown to interact with core members of an E3-type ubiquitin ligase complex which resulted in the hypothesis assuming a role of the Nictaba domain in glycoprotein degradation (Takahashi et al., 2004; Arabidopsis Interactome Mapping Consortium, 2011).

Ricin-B lectins. The ricin-B lectin family is one of the most widespread families of carbohydrate binding proteins in nature. The most famous member of this family is ricin, a toxic protein from castor bean (Ricinus communis L.) seeds, which was the very first lectin discovered in plants by Peter Hermann Stillmark in 1888. Ricin is a chimeric protein consisting of an A chain with enzymatic activity linked through a disulfide bridge with a B chain with lectin activity. This B chain consists of a duplicated ricin-B domain, responsible for the carbohydrate binding activity of the protein toward galactosylated structures. The enzymatic activity of ricin involves RNA $N$-glycosidase activity and is responsible for the removal of a highly conserved adenine residue from the sarcin/ricin loop of the $28 \mathrm{~S}$ ribosomal RNA. As a result, the ribosomes are no longer able to bind elongation factor 2 and protein synthesis is blocked. Because of their catalytic activity these chimeric proteins are also referred to as type 2 ribosomeinactivating proteins (RIPs), and are considered as toxic proteins if they succeed in entering the cell. The uptake of the protein by the host cell is aided by their lectinic B-chain which can specifically interact with glycoconjugate structures on the cell surface. Except for ricin and abrin (from the jequirity bean Abrus precatorius), most type 2 RIPs are only moderately or even weakly toxic (Van Damme et al., 2001; Stirpe and Battelli, 2006).

The family of ricin-B related lectins is widespread in the plant kingdom and has been characterized in detail for what concerns its biological activity and toxicity in several plant species, especially $R$. communis (castor bean), Abrus precatorius (jequirity bean), Viscum album (mistletoe), and Sambucus nigra (elderberry). Unlike the other soluble lectins described above, most ricin-B related proteins accumulate in the plant vacuole or are secreted to the extracellular space (Van Damme et al., 2008). Over the years the ricin-B domain 
was identified in numerous plants, animals, fungi, and bacteria. All these proteins with ricin-B domains are also classified as the R-type lectins (Cummings and Etzler, 2009).

Within the genus Sambucus (elderberry) an extended family of ricin-B related proteins, including several chimerolectins and hololectins has been identified (Shang and Van Damme, 2014). Detailed hapten inhibition assays and glycan array studies revealed that all these S. nigra proteins exhibit different carbohydrate binding properties, and allowed to classify the Sambucus lectins into three groups. A first group covers the lectins SNA-II and SNA-IV as well as the type 2 RIP SNA-V with specificity toward Gal/GalNAc and Gal/GalNAc-containing glycan structures. The second group comprises only the type 2 RIP SNA-I, which specifically interacts with terminal sialic acid residues (Neu5Ac; $\alpha 2-6$ ) linked to Gal/GalNAc. Finally, the type 2 RIP SNLRP represents a third specificity group with strong interaction with GlcNAc oligomers (Shang and Van Damme, 2014).

Several lines of evidence support the idea that ricin-B related lectins play a role in plant defense against pathogens (Chen etal., 2002b; Vandenbussche etal., 2004a,b) and insects (Wei et al., 2004; Shahidi-Noghabi et al., 2009). Over-expressing SNA-I' or SNA-V from S. nigra in transgenic tobacco (Samsun NN) plants enhances the tobacco plant's resistance against infection with tobacco mosaic virus. Though the antiviral effect is clearly related to the amount of protein expressed it cannot be related to an increased expression of pathogenesis-related proteins (Chen et al., 2002b; Vandenbussche et al., 2004a,b). Furthermore, no clear correlation was observed between in planta antiviral activity of the transgenic tobacco lines and the in vitro $\mathrm{N}$-glycosidase activity of the proteins toward genomic RNA of the tobacco mosaic virus, suggesting that the in planta antiviral activity of these RIPs may rely on a direct interaction with the virus (Vandenbussche et al., 2004a). At present the importance of the lectin activity in the antiviral activity of the proteins remains unclear.

The first evidence for the insecticidal activity of ricin-B related proteins came from feeding assays with ricin and cinnamomin (from Cinnamomum camphora tree). Ricin showed strong toxicity to several insects such as cowpea weevil (Callosobruchus macultatus), cotton boll weevil (Anthonomus grandis), house fly (Musca domestica), and larvae of the silkworm Bombyx mori (Wei et al., 2004). The differences in activity between ricin and cinnamomin could not be related to the enzymatic activity but rather were attributed to differences in the activity of the lectin chain of the proteins (Wei et al., 2004). ShahidiNoghabi et al. (2009) reported the enhanced resistance of transgenic tobacco plants overexpressing SNA-I or its isoform SNA-I' toward different pest insect species including aphids and caterpillars. Since mutation of the carbohydrate binding site can abolish or reduce the toxic effect, the entomotoxic properties of the proteins can be linked to their carbohydrate binding activity (Shahidi-Noghabi et al., 2008). In addition, the cytotoxic effects of S. nigra RIPs toward insect cells was accompanied by caspase 3-like protease-induced apoptosis (Shahidi-Noghabi etal., 2008, 2011). More research is needed to identify the interacting proteins for the Sambucus lectins on the cell surface.

\section{CONCLUSION}

Plant genomes encode a plethora of RLKs, RLPs, and lectins to protect themselves against the vast array of pathogenic bacteria, viruses, fungi, oomycetes, and pest insects. A key feature of the plant's innate immunity is the ability to recognize D/P/MAMPs of potential pathogens through PRRs, and subsequently respond in a highly sensitive and specific manner. Many advances have been made in the understanding how different proteins function in plant innate immunity. As more structural and biochemical data become available, common themes are emerging on receptor organization, ligand perception and binding, receptor activation, and intracellular defense signaling. It is clear now that PRRs are ultradynamic multiprotein structures which often use phosphorylation to activate downstream signaling.

A first interaction between the pathogen and the plant occurs at the level of the cell wall and the plasma membrane where extracellular effectors, DAMPs, and P/MAMPs will be recognized by membrane-bound receptors (Figure 1; Tables 1 and 2), among which a large group of RLPs and RLKs some of which carry an extracellular lectin domain. Though different lectin motifs have been recognized, only the LysM domain was unambiguously shown to be dependent on carbohydrate interactions for recognition of fungal and bacterial components and subsequent signal transmission into the plant cell. Interestingly, the LysM motif shows high specificity for chito-oligosaccharides, an abundant component in different pathogens but absent from plants. Other (lectin) receptor kinases/proteins probably depend on protein-protein interactions to recognize specific ligands. Though our knowledge on receptor kinase function and signaling has greatly improved, several issues still remain with respect to the potential ligands for pathogen recognition and the downstream signaling events, especially for those receptors lacking the kinase domain.

In addition to the lectin motifs present at the level of the cell wall/plasma membrane, plants synthesize well-defined soluble lectins upon exposure to multiple abiotic and biotic stresses (Table 3). Most of these inducible lectins reside in the nucleus and the cytosol of the plant cell and evidence is emerging for their role in signal transduction inside the plant cell as part of multiple plant defense pathways. Hence protein-carbohydrate interactions should not only be envisaged at the level of the interaction between the pathogen and the plant cell, but also play an important role inside the plant cell as part of the intracellular signaling resulting from the recognition of plant attackers. At least for some cytoplasmic lectins (Nictaba-related proteins, EUL-related proteins, amaranthins) it was shown that they are also translocated inside the plant nucleus. The Nictabarelated proteins in particular have been shown to interact with glycosylated histones, and therefore are suggested to act as chromatin remodelers, enabling altered gene expression as a result of stress signaling. Surveying the plant genome sequences also revealed that most lectin domains are part of larger proteins, consisting of one or more lectin domains linked to un-related protein domains, most often with unknown functions. Future challenges include the characterization of the ligands for these soluble lectins or lectin domains present as part of a larger protein to elucidate the biological relevance of these interactions. 
Large-scale experiments integrating genomics, biochemistry, cell biology, structural biology, and bioinformatics will enable to elucidate the physiological importance of the lectin motifs in protein-carbohydrate interactions in signal transduction and plant defense.

\section{ACKNOWLEDGMENTS}

This work was supported by the Fund for Scientific Research Flanders and the Research Council of Ghent University. N. Lannoo acknowledges the receipt of a Postdoctoral fellowship from the Fund for Scientific Research - Flanders.

\section{REFERENCES}

Al Atalah, B., De Vleesschauwer, D., Xu, J., Fouquaert, E., Höfte, M., and Van Damme, E. J. (2014a). Transcriptional behavior of EUL-related rice lectins toward important abiotic and biotic stresses. J. Plant Physiol. 171, 986-992. doi: 10.1016/j.jplph.2014.04.004

Al Atalah, B., Vanderschaeghe, D., Bloch, Y., Proost, P., Plas, K., Callewaert, N., etal. (2014b). Characterization of a type D1A EUL-related lectin from rice expressed in Pichia pastoris. Biol. Chem. 395, 413-424. doi: 10.1515/hsz2013-0267

Al Atalah, B., Fouquaert, E., Vanderschaeghe, D., Proost, P., Balzarini, J., Smith, D. F., et al. (2011). Expression analysis of the nucleocytoplasmic lectin "Orysata" from rice in Pichia pastoris. FEBS J. 278, 2064-2079. doi: $10.1111 / j .1742-4658.2011 .08122 . x$

Al Atalah, B., Rougé, P., Smith, D. F., Proost, P., Lasanajak, Y., and Van Damme, E. J. M. (2012). Expression analysis of a type S2 EUL-related lectin from rice in Pichia pastoris. Glycoconj. J. 29, 467-479. doi: 10.1007/s10719-0129405-2

Albert, M. (2013). Peptides as triggers of plant defence. J. Exp. Bot. 64, 5269-5279. doi: $10.1093 /$ jxb/ert275

Arabidopsis Interactome Mapping Consortium. (2011). Evidence for network evolution in an Arabidopsis interactome map. Science 333, 601-607. doi: $10.1126 /$ science. 1203877

Bar, M., Sharfman, M., Ron, M., and Avni, A. (2010). BAK1 is required for the attenuation of ethylene-inducing xylanase (Eix)-induced defense responses by the decoy receptor LeEix1. Plant J. 63, 791-800. doi: 10.1111/j.1365-313X.2010. 04282.x

Bencharki, B., Boissinot, S., Revollon, S., Ziegler-Graff, V., Erdinger, M., Wiss, L., et al. (2010). Phloem protein partners of Cucurbit aphid borne yellows virus: possible involvement of phloem proteins in virus transmission by aphids. Mol. Plant Microbe Interact. 23, 799-810. doi: 10.1094/MPMI-236-0799

Beneteau, J., Renard, D., Marché, L., Douville, E., Lavenant, L., Rahbé, Y., et al. (2010). Binding properties of the $\mathrm{N}$-acetylglucosamine and high-mannose $\mathrm{N}$ glycan PP2-A1 phloem lectin in Arabidopsis. Plant Physiol. 153, 1345-1361. doi: 10.1104/pp.110.153882

Berendzen, K. W., Böhmer, M., Wallmeroth, N., Peter, S., Vesić, M., Zhou, Y., et al. (2012). Screening for in planta protein-protein interactions combining bimolecular fluorescence complementation with flow cytometry. Plant Methods 8:25. doi: $10.1186 / 1746-4811-8-25$

Block, A., and Alfano, J. R. (2011). Plant targets for Pseudomonas syringae type III effectors: virulence targets or guarded decoys? Curr. Opin. Microbiol. 14, 39-46. doi: 10.1016/j.mib.2010.12.011

Block, A., Toruño, T. Y., Elowsky, C. G., Zhang, C., Steinbrenner, J., Beynon, J., et al. (2013). The Pseudomonas syringae type III effector HopD1 suppresses effector-triggered immunity, localizes to the endoplasmic reticulum, and targets the Arabidopsis transcription factor NTL9. New Phytol. 201, 1358-1370. doi: $10.1111 /$ nph.12626

Böhm, H., Albert, I., Fan, L., Reinhard, A., and Nürnberger, T. (2014). Immune receptor complexes at the plant cell surface. Curr. Opin. Plant Biol. 20, 47-54. doi: 10.1016/j.pbi.2014.04.007

Boller, T., and Felix, G. (2009). A renaissance of elicitors: perception of microbe-associated molecular patterns and danger signals by pattern-recognition receptors. Annu. Rev. Plant Biol. 60, 379-406. doi: 10.1146/annurev.arplant.57.032905.105346
Bouwmeester, K., de Sain, M., Weide, R., Gouget, A., Klamer, S., Canut, H., et al. (2011). The lectin receptor kinase LecRK-I.9 is a novel Phytophthora resistance component and a potential host target for a RXLR effector. PLoS Pathog. 7:e1001327. doi: 10.1371/journal.ppat.1001327

Bouwmeester, K., and Govers, F. (2009). Arabidopsis L-type lectin receptor kinases: phylogeny, classification, and expression profiles. J. Exp. Bot. 60, 4383-4396. doi: 10.1093/jxb/erp277

Brotman, Y., Landau, U., Pnini, S., Lisec, J., Balazadeh, S., Mueller-Roeber, B., et al. (2012). The LysM receptor-like kinase LysM RLK1 is required to activate defense and abiotic-stress responses induced by overexpression of fungal chitinases in Arabidopsis plants. Mol. Plant 5, 1113-1124. doi: 10.1093/mp/sss021

Buist, G., Steen, A., Kok, J., and Kuipers, O. P. (2008). LysM, a widely distributed protein motif for binding to (peptido)glycans. Mol. Microbiol. 68, 838-847. doi: 10.1111/j.1365-2958.2008.06211.x

Cambi, A., Koopman, M., and Figdor, C. G. (2005). How C-type lectins detect pathogens. Cell. Microbiol. 7, 481-488. doi: 10.1111/j.1462-5822.2005.00506.x

Cao, Y., Tanaka, K., Nguyen, C. T., and Stacey, G. (2014). Extracellular ATP is a central signaling molecule in plant stress responses. Curr. Opin. Plant Biol. 20, 82-87. doi: 10.1016/j.pbi.2014.04.009

Chen, X., Zuo, S., Schwessinger, B., Chern, M., Canlas, P. E., Ruan, D., et al. (2014). An XA21-associated kinase (OsSERK2) regulates immunity mediated by the XA21 and XA3 immune receptors. Mol. Plant 7, 874-892. doi: $10.1093 / \mathrm{mp} / \mathrm{ssu} 003$

Chen, Y., Peumans, W. J., Hause, B., Bras, J., Kumar, M., Proost, P., et al. (2002a). Jasmonic acid methyl ester induces the synthesis of a cytoplasmic/nuclear chitooligosaccharide-binding lectin in tobacco leaves. FASEB J. 16, 905-907.

Chen, Y., Peumans, W. J., and Van Damme, E. J. M. (2002b). The Sambucus nigra type-2 ribosome-inactivating protein SNA-I' exhibits in planta antiviral activity in transgenic tobacco. FEBS Lett. 516, 27-30. doi: 10.1016/S0014-5793(02) $02455-9$

Chinchilla, D., Bauer, Z., Regenass, M., Boller, T., and Felix, G. (2006). The Arabidopsis receptor kinase FLS2 binds flg22 and determines the specificity of flagellin perception. Plant Cell 18, 465-476. doi: 10.1105/tpc.105.036574

Chinchilla, D., Zipfel, C., Robatzek, S., Kemmerling, B., Nürnberger, T., Jones, J. D., et al. (2007). A flagellin-induced complex of the receptor FLS2 and BAK1 initiates plant defence. Nature 448, 497-500. doi: 10.1038/nature05999

Choi, J., Tanaka, K., Cao, Y., Qi, Y., Qiu, J., Liang, Y., et al. (2014). Identification of a plant receptor for extracellular ATP. Science 343, 290-294. doi: 10.1126/science.343.6168.290

Cui, F., Wu, S., Sun, W., Coaker, G., Kunkel, B., He, P., et al. (2013). The Pseudomonas syringae type III effector AvrRpt2 promotes pathogen virulence via stimulating Arabidopsis auxin/indole acetic acid protein turnover. Plant Physiol. 162, 10181029. doi: $10.1104 /$ pp.113.219659

Cummings, R. D., and Etzler, M. E. (2009). "R-type lectins," in Essentials of Glycobi$o l o g y$, 2nd Edn, Chap. 28, eds E. Varki, R. D. Cummings, J. D. Esko, H. H. Freeze, P. Stanley, C. R. Bertozzi., et al. (Cold Spring Harbor, NY: Cold Spring Harbor Laboratory Press).

Dangl, J. L., Horvath, D. M., and Staskawicz, B. J. (2013). Pivoting the plant immune system from dissection to deployment. Science 341, 746-751. doi: $10.1126 /$ science. 1236011

Degiacomi, M. T., Iacovache, I., Pernot, L., Chami, M., Kudryashev, M., Stahlberg, H., et al. (2013). Molecular assembly of the aerolysin pore reveals a swirling membrane-insertion mechanism. Nat. Chem. Biol. 9, 623-629. doi: 10.1038/nchembio. 1312

Delporte, A., De Vos, W. H., and Van Damme, E. J. M. (2014a). In vivo interaction between the tobacco lectin and the core histone proteins. J. Plant Physiol. 171, 986-992. doi: 10.1016/j.jplph.2014.04.008

Delporte, A., Van Holle, S., Lannoo, N., and Van Damme, E. J. M. (2014b). The tobacco lectin, prototype of the family of Nictaba-related proteins. Curr. Prot. Pept. Sci. (in press).

de Souza Filho, G. A., Ferreira, B. S., Dias, J. M. R., Queiroz, K. S., Branco, A. T., Bressan-Smith, R. E., et al. (2003). Accumulation of SALT protein in rice plants as a response to environmental stresses. Plant Sci. 164, 623-628. doi: 10.1016/S0168-9452(03)00014-1

Dubery, I. A., Sanabria, N. M., and Huang, J.-C. (2012). "Chapter 6: nonself perception in plant innate immunity," in Self and Nonself, ed. C. López-Larrea (Austin, TX: Landes Bioscience; New York, NY: Springer Science+Business Media). 
Ellgaard, L., and Frickel, E. M. (2003). Calnexin, calreticulin, and ERp57: teammates in glycoprotein folding. Cell Biochem. Biophys. 39, 223-247. doi: 10.1385/CBB:39:3:223

Endre, G., Kereszt, A., Kevei, Z., Mihacea, S., Kaló, P., and Kiss, G. B. (2002). A receptor kinase gene regulating symbiotic nodule development. Nature 417, 962-966. doi: 10.1038/nature00842

Esen, A., and Blanchard, D. J. (2000). A specific $\beta$-glucosidase-aggregating factor is responsible for the $\beta$-glucosidase null phenotype in maize. Plant Physiol. 122 , 563-572. doi: 10.1104/pp.122.2.563

Feng, H., Xu, W.-Z., Lin, H.-H., and Chong, K. (2009). Transcriptional regulation of wheat VER2 promoter in rice in response to abscisic acid, jasmonate, and light. J. Genet. Genomics 36, 371-377. doi: 10.1016/S1673-8527(08)60126-5

Fouquaert, E., Peumans, W. J., Smith, D. F., Proost, P., Savvides, S. N., and Van Damme, E. J. M. (2008). The "old" Euonymus europaeus agglutinin represents a novel family of ubiquitous plant proteins. Plant Physiol. 147, 1316-1324. doi: $10.1104 / \mathrm{pp} .108 .116764$

Fouquaert, E., and Van Damme, E. J. M. (2012). Promiscuity of the euonymus carbohydrate-binding domain. Biomolecules 2, 415-434. doi 10.3390/biom 2040415

Fradin, E. F., Zhang, Z., Juarez Ayala, J. C., Castroverde, C. D., Nazar, R. N., Robb, J., et al. (2009). Genetic dissection of Verticillium wilt resistance mediated by tomato Ve1. Plant Physiol. 150, 320-332. doi: 10.1104/pp.109.136762

Gilardoni, P. A., Hettenhausen, C., Baldwin, I. T., and Bonaventure, G. (2011). Nicotiana attenuata LECTIN RECEPTOR KINASE 1 suppresses the insect-mediated inhibition of induced defense responses during Manduca sexta herbivory. Plant Cell 23, 3512-3532. doi: 10.1105/tpc.111.088229

Gómez-Gómez, L., Bauer, Z., and Boller, T. (2001). Both the extracellular leucine-rich repeat domain and the kinase activity of FLS2 are required for flagellin binding and signaling in Arabidopsis. Plant Cell 13, 1155-1163. doi: 10.1105/tpc.13.5.1155

Grant, S. R., Fisher, E. J., Chang, J. H., Mole, B. M., and Dangl, J. L. (2006) Subterfuge and manipulation: type III effector proteins of phytopathogenic bacteria. Annu. Rev. Microbiol. 60, 425-449. doi: 10.1146/annurev.micro.60.080805. 142251

Gudesblat, G. E., Torres, P. S., and Vojnov, A. A. (2009). Xanthomonas campestris overcomes Arabidopsis stomatal innate immunity through a DSF cellto-cell signal-regulated virulence factor. Plant Physiol. 149, 1017-1027. doi $10.1104 /$ pp. 108.126870

Gust, A. A., Willmann, R., Desaki, Y., Grabherr, H. M., and Nürnberger, T. (2012). Plant LysM proteins: modules mediating symbiosis and immunity. Trends Plant Sci. 17, 495-502. doi: 10.1016/j.tplants.2012.04.003

Halter, T., Imkampe, J., Mazzotta, S., Wierzba, M., Postel, S., Bücherl, C., et al. (2014). The leucine-rich repeat receptor kinase BIR2 is a negative regulator of BAK1 in plant immunity. Curr. Biol. 24, 134-143. doi: 10.1016/j.cub.2013.11.047

Han, Z., Sun, Y., and Chai, J. (2014). Structural insight into the activation of plant receptor kinases. Curr. Opin. Plant Biol. 20, 55-63. doi: 10.1016/j.pbi.2014. 04.008

Häweker, H., Rips, S., Koiwa, H., Salomon, S., Saijo, Y., Chinchilla, D., et al. (2010) Pattern recognition receptors require $\mathrm{N}$-glycosylation to mediate plant immunity. J. Biol. Chem. 285, 4629-4636. doi: 10.1074/jbc.M109.063073

Hayafune, M., Berisio, R., Marchetti, R., Silipo, A., Kayama, M., Desaki, Y., et al. (2014). Chitin-induced activation of immune signaling by the rice receptor CEBiP relies on a unique sandwich-type dimerization. Proc. Natl. Acad. Sci. U.S.A. 111, E404-E413. doi: 10.1073/pnas.1312099111

Howell, S. H. (2013). Endoplasmic reticulum stress responses in plants. Annu. Rev. Plant Biol. 64, 477-499. doi: 10.1146/annurev-arplant-050312-120053

Huang, P., Ju, H.-W., Min, J.-H., Zhang, X., Kim, S.-H., Yang, K.-Y., et al. (2013). Overexpression of L-type lectin-like protein kinase 1 confers pathogen resistance and regulates salinity response in Arabidopsis thaliana. Plant Sci. 203-204, 98-106. doi: 10.1016/j.plantsci.2012.12.019

Huang, P.-Y., Yeh, Y.-H., Liu, A.-C., Cheng, C.-P., and Zimmerli, L. (2014). The Arabidopsis LecRK-VI.2 associates with the pattern-recognition receptor FLS2 and primes Nicotiana benthamiana pattern-triggered immunity. Plant J. 79, 243 255. doi: $10.1111 /$ tpj.12557

Jiang, J. F., Han, Y., Xing, L. J., Xu, Y. Y., Xu, Z. H., and Chong, K. (2006) Cloning and expression of a novel cDNA encoding a mannose-specific jacalinrelated lectin from Oryza sativa. Toxicon 47, 133-139. doi: 10.1016/j.toxicon. 2005.10.010
Jiang, J. F., Xu, Y. Y., and Chong, K. (2007). Overexpression of OsJAC1, a lectin gene, suppresses the coleoptiles and stem elongation in rice. J. Integr. Plant Biol. 49, 230-237. doi: 10.1111/j.1744-7909.2007.00428.x

Jin, H., Hong, Z., Su, W., and Li, J. (2009). A plant-specific calreticulin is a key retention factor for a defective brassinosteroid receptor in the endoplasmic reticulum. Proc. Natl. Acad. Sci. U.S.A. 106, 13612-13617. doi: 10.1073/pnas. 0906144106

Kaku, H., Nishizawa, Y., Ishii-Minami, N., Akimoto-Tomiyama, C., Dohmae, N., Takio, K., etal. (2006). Plant cells recognize chitin fragments for defense signaling through a plasma membrane receptor. Proc. Natl. Acad. Sci. U.S.A. 103, 11086-11091. doi: 10.1073/pnas. 0508882103

Kanagawa, M., Liu, Y., Hanashima, S., Ikeda, A., Chai, W., Nakano, Y., et al. (2014). Structural basis for multiple sugar recognition of jacalin-related human ZG16p lectin. J. Biol. Chem. 289, 16954-16965. doi: 10.1074/jbc.M113.539114

Kanzaki, H., Saitoh, H., Takahashi, Y., Berberich, T., Ito, A., Kamoun, S., et al. (2008) NbLRK1, a lectin-like receptor kinase protein of Nicotiana benthamiana, interacts with Phytophthora infestans INF1 elicitin and mediates INF1-induced cell death. Planta 228, 977-987. doi: 10.1007/s00425-008-0797-y

Kapoor, M., Ellgaard, L., Gopalakrishnapai, J., Schirra, C., Gemma, E., Oscarson, S., etal. (2004). Mutational analysis provides molecular insight into the carbohydrate-binding region of calreticulin: pivotal roles of tyrosine-109 and aspartate-135 in carbohydrate recognition. Biochemistry 43, 97-106. doi: 10.1021/bi0355286

Kim, Y. T., Oh, J., Kim, K. H., Uhm, J. Y., and Lee, B. M. (2009). Isolation and characterization of NgRLK1, a receptor-like kinase of Nicotiana glutinosa that interacts with the elicitin of Phytophthora capsici. Mol. Biol. Rep. 37, 717-727. doi: 10.1007/s11033-009-9570-y

Kittur, F. S., Yu, H. Y., Bevan, D. R., and Esen, A. (2009). Homolog of the maize $\beta$ glucosidase aggregating factor from sorghum is a jacalin-related GalNAc-specific lectin but lacks protein aggregating activity. Glycobiology 19, 277-287. doi: $10.1093 /$ glycob/cwn132

Knogge, W., and Scheel, D. (2006). LysM receptors recognize friend and foe. Proc. Natl. Acad. Sci. U.S.A. 103, 10829-10830. doi: 10.1073/pnas.0604601103

Kouzai, Y., Nakajima, K., Hayafune, M., Ozawa, K., Kaku, H., Shibuya, N., et al. (2014). CEBiP is the major chitin oligomers-binding protein in rice and plays a main role in the perception of chitin oligomers. Plant Mol. Biol. 84, 519-528. doi: 10.1007/s11103-013-0149-6

Krol, E., Mentzel, T., Chinchilla, D., Boller, T., Felix, G., Kemmerling, B., et al. (2010). Perception of the Arabidopsis danger signal peptide 1 involves the pattern recognition receptor AtPEPR1 and its close homologue AtPEPR2. J. Biol. Chem. 285, 13471-13479. doi: 10.1074/jbc.M109.097394

Lannoo, N., Peumans, W. J., and Van Damme, E. J. M. (2008). Do F-box proteins with a C-terminal domain homologous with the tobacco lectin play a role in protein degradation in plants? Biochem. Soc. Trans. 36, 843-847. doi: 10.1042/BST0360843

Lannoo, N., Peumans, W. J., Van Pamel, E., Alvarez, R., Xiong, T., Hause, G., et al. (2006). Localization and in vitro binding studies suggest that the cytoplasmic/nuclear tobacco lectin can interact in situ with high-mannose and complex N-glycans. FEBS Lett. 580, 6329-6337. doi: 10.1016/j.febslet.2006. 10.044

Lannoo, N., and Van Damme, E. J. (2010). Nucleocytoplasmic plant lectins. Biochem. Biophys. Acta 1800, 190-201. doi: 10.1016/j.bbagen.2009. 07.021

Lannoo, N., Vandenborre, G., Miersch, O., Smagghe, G., Wasternack, C., Peumans, W. J., et al. (2007). The jasmonate-induced expression of the Nicotiana tabacum leaf lectin. Plant Cell Physiol. 48, 1207-1218. doi: 10.1093/pcp/ pcm090

Lee, J. R., Boltz, K. A., and Lee, S. Y. (2014). Molecular chaperone function of Arabidopsis thaliana phloem protein 2-A1 encodes a protein similar to phloem lectin. Biochem. Biophys. Res. Commun. 443, 18-21. doi: 10.1016/j.bbrc.2013. 11.034

Lee, R. H., Wang, C. H., Huang, L. T., and Chen, S. C. (2001). Leaf senescence in rice plants: cloning and characterization of senescence up-regulated genes. J. Exp. Bot. 52, 1117-1121. doi: 10.1093/jexbot/52.358.1117

Lee, S. W., Han, S. W., Sririyanum, M., Park, C. J., Seo, Y. S., and Ronald, P. C. (2009). A type I-secreted, sulfated peptide triggers XA21-mediated innate immunity. Science 326, 850-853. doi: 10.1126/science. 1173438 
Li, D., Wang, X., Yuan, D., Zhang, L., Jiang, X., Tao, Z., et al. (2014). Overexpression of ArathEULS3 confers ABA sensitivity and drought tolerance in Arabidopsis. Plant Cell Tissue Organ Cult. 117, 431-442. doi: 10.1007/s11240-0140453-0

Li, J., Zhao-Hui, C., Batoux, M., Nekrasov, V., Roux, M., Chinchilla, D., et al. (2009). Specific ER quality control components required for biogenesis of the plant innate immune receptor EFR. Proc. Natl. Acad. Sci. U.S.A. 106, 1597315978. doi: 10.1073/pnas.0905532106

Limpens, E., Franken, C., Smit, P., Willemse, J., Bisseling, T., and Geurts, R. (2003). LysM domain receptor kinases regulating rhizobial Nod factor-induced infection. Science 302, 630-633. doi: 10.1126/science.1090074

Liu, B., Li, J. F., Ao, Y., Qu, J., Li, Z., Su, J., et al. (2012a). Lysin motif-containing proteins LYP4 and LYP6 play dual roles in peptidoglycan and chitin perception in rice innate immunity. Plant Cell 24, 3406-3419. doi: 10.1105/tpc.112.102475

Liu, T., Liu, Z., Song, C., Hu, Y., Han, Z., She, J., et al. (2012b). Chitin-induced dimerization activates a plant immune receptor. Science 336, 1160-1164. doi $10.1126 /$ science. 1218867

Liu, Y., and Li, J. (2014). Endoplasmic reticulum-mediated protein quality control in Arabidopsis. Front. Plant Sci. 5:162. doi: 10.3389/fpls.2014. 00162

Ma, Q. H., Tian, B., and Li, Y. L. (2010). Overexpression of a wheat jasmonateregulated lectin increases pathogen resistance. Biochimie 92, 187-193. doi: 10.1016/j.biochi.2009.11.008

Ma, Q. H., Zhen, W. B., and Liu, Y. C. (2013). Jacalin domain in wheat jasmonateregulated protein Ta-JA1 confers agglutinating activity and pathogen resistance. Biochimie 95, 359-365. doi: 10.1016/j.biochi.2012.10.014

Macho, A. P., and Zipfel, C. (2014). Plant PRRs and the activation of innate immune signaling. Mol. Cell 54, 263-272. doi: 10.1016/j.molcel.2014. 03.028

Madsen, E. B., Madsen, L. H., Radutoiu, S., Olbryt, M., Rakwalska, M., Szczyglowski, K., et al. (2003). A receptor kinase gene of the LysM type is involved in legume perception of rhizobial signals. Nature 425, 637-640. doi: 10.1038/nature02045

Malinovsky, F. G., Fangel, J. U., and Willats, W. G. T. (2014). The role of the cell wall in plant immunity. Front. Plant Sci. 5:178. doi: 10.3389/fpls.2014.00178

Melotto, M., Underwood, W., Koczan, J., Nomura, K., and He, S. Y. (2006). Plant stomata function in innate immunity against bacterial invasion. Cell 126, 969 980. doi: 10.1016/j.cell.2006.06.054

Miya, A., Albert, P., Shinya, T., Desaki, Y., Ichimura, K., Shirasu, K., et al. (2007). CERK1, a LysM receptor kinase, is essential for chitin elicitor signaling in Arabidopsis. Proc. Natl. Acad. Sci. U.S.A. 104, 19613-19618. doi: 10.1073/pnas.0705147104

Mulder, L., Lefebvre, B., Cullimore, J., and Imberty, A. (2006). LysM domains of Medicago truncatula NFP protein involved in Nod factor perception. Glycosylation state, molecular modeling and docking of chitooligosaccharides and Nod factors. Glycobiology 16, 801-809. doi: 10.1093/glycob/cwl006

Muthamilarasan, M., and Prasad, M. (2013). Plant innate immunity: an updated insight into defense mechanism. J. Biosci. 38, 433-449. doi: 10.1007/s12038-0139302-2

Nagano, A. J., Fukao, Y., Fujiwara, M., Nishimura, M., and Hara-Nishimura, I. (2008). Antagonistic jacalin-related lectins regulate the size of ER body-type $\beta$ glucosidase complexes in Arabidopsis thaliana. Plant Cell Physiol. 49, 969-980. doi: $10.1093 / \mathrm{pcp} / \mathrm{pcn} 075$

Navarro-Gochicoa, M. T., Camut, S., Timmers, A. C. J., Niebel, A., Herye, C., Boutet, E., et al. (2003). Characterization of four lectin-like receptor kinases expressed in roots of Medicago truncatula structure, location, regulation of expression, and potential role in the symbiosis with Sinorhizobium meliloti. Plant Physiol. 133, 1893-1910. doi: 10.1104/pp.103.027680

Newman, M.-A., Sundelin, T., Nielsen, J. T., and Erbs, G. (2013). MAMP (microbeassociated molecular pattern) triggered immunity in plants. Front. Plant Sci. 4:139. doi: 10.3389/fpls.2013.00139

Nühse, T. S. (2012). Cell wall integrity signaling and innate immunity in plants. Front. Plant Sci. 3:280. doi: 10.3389/fpls.2012.00280

Paparella, C., Savatin, D. V., Marti, L., De Lorenzo, G., and Ferrari, S. (2014). The Arabidopsis LYSIN MOTIF-CONTAINING RECEPTOR-LIKE KINASE 3 regulates the cross talk between immunity and abscisic acid responses. Plant Physiol. 165, 262-276. doi: 10.1104/pp.113.233759

Park, C. J., and Ronald, P. C. (2012). Cleavage and nuclear localization of the rice XA21 immune receptor. Nat. Commun. 3:920. doi: 10.1038/ncomms1932
Petutschnig, E. K., Jones, A. M., Serazetdinova, L., Lipka, U., and Lipka, V. (2010). The lysin motif receptor-like kinase (LysM-RLK) CERK1 is a major chitin-binding protein in Arabidopsis thaliana and subject to chitin-induced phosphorylation. J. Biol. Chem. 285, 28902-28911. doi: 10.1074/jbc.M110.116657

Peumans, W. J., and Van Damme, E. J. M. (1995). Lectins as plant defense proteins. Plant Physiol. 109, 347-352. doi: 10.1104/pp.109.2.347

Puthoff, D. P., Sardesai, N., Subramanyam, S., Nemacheck, J. A., and Williams, C. E. (2005). Hfr-2, a wheat cytolytic toxin-like gene, is up-regulated by virulent Hessian fly larval feeding. Mol. Plant Pathol. 6, 411-423. doi: 10.1111/j.13643703.2005.00289.x

Qin, Q. M., Zhang, Q., Zhao, W. S., Wang, Y. Y., and Peng, Y. L. (2003). Identification of a lectin gene induced in rice in response to Magnaporthe grisea infection. Acta Bot. Sin. 45, 76-81.

Qiu, Y., Xi, J., Du, L., Roje, S., and Poovaiah, B. W. (2012). A dual regulatory role of Arabidopsis calreticulin-2 in plant innate immunity. Plant J. 69, 489-500. doi: 10.1111/j.1365-313X.2011.04807.x

Radutoiu, S., Madsen, L. H., Madsen, E. B., Felle, H. H., Umehara, Y., Gronlund, M., etal. (2003). Plant recognition of symbiotic bacteria requires two LysM receptor-like kinases. Nature 425, 585-592. doi: 10.1038/ nature 02039

Regente, M., Taveira, G. B., Pinedo, M., Elizalde, M. M., Ticchi, A. J., Diz, M. S. S., et al. (2014). A sunflower lectin with antifungal properties and putative medical mycology applications. Curr. Microbiol. 69, 88-95. doi: 10.1007/s00284014-0558-Z

Roberts, D. D., and Goldstein, I. J. (1983). Adenine binding sites of the lectin from lima beans (Phaseolus lunatus). J. Biol. Chem. 258, 13820-13824.

Ron, M., and Avni, A. (2004). The receptor for the fungal elicitor ethylene-inducing xylanase is a member of a resistance-like gene family in tomato. Plant Cell 16, 1604-1615. doi: 10.1105/tpc.022475

Rotblat, B., Enshell-Seijffers, D., Gershoni, J. M., Schuster, S., and Avni, A. (2002). Identification of an essential component of the elicitation active site of the EIX protein elicitor. Plant J. 32, 1049-1055. doi: 10.1046/j.1365-313X.2002.01490.x

Ryan, C. A. (2000). The systemin signaling pathway: differential activation of plant defensive genes. Biochim. Biophys. Acta 1477, 112-121. doi: 10.1016/S01674838(99)00269-1

Scheer, J. M., and Ryan, C. A. Jr. (2002). The systemin receptor SR160 from Lycopersicon peruvianum is a member of the LRR receptor kinase family. Proc. Natl. Acad. Sci. U.S.A. 99, 9585-9590. doi: 10.1073/pnas.132266499

Schouppe, D., Ghesquière, B., Menschaert, G., De Vos, W. H., Bourque, S., Trooskens, G., et al. (2011). Interaction of the tobacco lectin with histone proteins. Plant Physiol. 155, 1091-1102. doi: 10.1104/pp.110.170134

Schulze, B., Mentzel, T., Jehle, A. K., Mueller, K., Beeler, S., Boller, T., et al. (2010). Rapid heteromerization and phosphorylation of ligand-activated plant transmembrane receptors and their associated kinase BAK1. J. Biol. Chem. 285, 9444-9451. doi: 10.1074/jbc.M109.096842

Shahidi-Noghabi, S., Van Damme, E. J. M., De Vos, W. H., and Smagghe, G. (2011). Internalization of Sambucus nigra agglutinins I and II in insect midgut cells. Arch. Insect Biochem. Physiol. 76, 211-222. doi: 10.1002/ arch. 20405

Shahidi-Noghabi, S., Van Damme, E. J. M., and Smagghe, G. (2008). Carbohydrate-binding activity of the type-2 ribosome-inactivating protein SNA-I from elderberry (Sambucus nigra) is a determining factor for its insecticidal activity. Phytochemistry 69, 2972-2978. doi: 10.1016/j.phytochem.2008. 09.012

Shahidi-Noghabi, S., Van Damme, E. J. M., and Smagghe, G. (2009). Expression of Sambucus nigra agglutinin (SNA-I') from elderberry bark in transgenic tobacco plants results in enhanced resistance to different insect species. Transgenic Res. 18, 249-259. doi: 10.1007/s11248-008-9215-2

Shang, C., and Van Damme, E. J. M. (2014). Comparative analysis of carbohydrate binding properties of Sambucus nigra lectins and ribosome-inactivating proteins. Glycoconj. J. 31, 345-354. doi: 10.1007/s10719-014-9527-952

Sherman-Broyles, S., Boggs, N., Farkas, A., Liu, P., Vrebalov, J., Nasrallah, M. E., et al. (2007). S locus genes and the evolution of self-fertility in Arabidopsis thaliana. Plant Cell 19, 94-106. doi: 10.1105/tpc.106.048199

Shimizu, T., Nakano, T., Takamizawa, D., Desaki, Y., Ishii-Minami, N., Nishizawa, Y., et al. (2010). Two LysM receptor molecules, CEBiP and OsCERK1, cooperatively regulate chitin elicitor signaling in rice. Plant J. 64, 204-214. doi: 10.1111/j.1365313X.2010.04324.X 
Shinya, T., Motoyama, N., Ikeda, A., Wada, M., Kamiya, K., Hayafune, M., et al. (2012). Functional characterization of CEBiP and CERK1 homologs in Arabidopsis and rice reveals the presence of different chitin receptor systems in plants. Plant Cell Physiol. 53, 1696-1706. doi: 10.1093/pcp/pcs113

Singh, P., Kuo, Y. C., Mishra, S., Tsai, C. H., Chien, C. C., Chen, C. W., et al (2012). The lectin-receptor kinase-VI.2 is required for priming and positively regulates Arabidopsis pattern-triggered immunity. Plant Cell 24, 1256-1270. doi 10.1105/tpc.112.095778

Singh, P., and Zimmerli, L. (2013). Lectin receptor kinases in plant innate immunity. Front. Plant Sci. 4:124. doi: 10.3389/fpls.2013.00124

Smith, J. M., Salamango, D. J., Leslie, M. E., Collins, C. A., and Heese, A. (2014). Sensitvity to Flg22 is modulated by ligand-induced degradation and de novo synthesis of the endogenous flagellin-receptor FLAGELLIN-SENSING2. Plant Physiol. 164, 440-454. doi: 10.1104/pp.113.229179

Song, M., Xu, W., Xiang, Y., Jia, H., Zhang, L., and Ma, Z. (2014). Association of jacalin-related lectins with wheat responses to stresses revealed by transcriptional profiling. Plant Mol. Biol. 84, 95-110. doi: 10.1007/s11103-013-0121-5

Stefanowicz, K., Lannoo, N., Proost, P., and Van Damme, E. J. M. (2012) Arabidopsis F-box protein containing a Nictaba-related lectin domain interacts with N-acetyllactosamine structures. FEBS Open Bio 2, 151-158. doi: 10.1016/j.fob.2012.06.002

Stirpe, F., and Battelli, M. G. (2006). Ribosome-inactivating proteins: progress and problems. Cell. Mol. Life Sci. 63, 1850-1866. doi: 10.1007/s00018-0066078-7

Stracke, S., Kistner, C., Yoshida, S., Mulder, L., Sato, S., Kaneko, T., et al. (2002) A plant receptor-like kinase required for both bacterial and fungal symbiosis Nature 417, 959-962. doi: 10.1038/nature00841

Subramanyam, S., Smith, D. F., Clemens, J. C., Webb, M. A., Sardesai, N., and Williams, C. E. (2008). Functional characterization of HFR1, a high-mannose N-glycan-specific wheat lectin induced by Hessian fly larvae. Plant Physiol. 147, 1412-1426. doi: 10.1104/pp.108.116145

Sun, X., Cao, Y., Yang, Z., Xu, C., Li, X., Wang, S., et al. (2004). Xa26, a gene conferring resistance to Xanthomonas oryzae pv. oryzae in rice, encodes an LRR receptor kinase-like protein. Plant J. 37, 517-527. doi: 10.1046/j.1365-313X.2003. 01976.x

Sun, X.-L., Yu, Q.-Y., Tang, L.-L., Ji, W., Bai, X., Cai, H., et al. (2013). GsSRK, a G-type lectin S-receptor-like serine/threonine protein kinase, is a positive regulator of plant tolerance to salt stress. J. Plant Physiol. 170, 505-515. doi: 10.1016/j.jplph.2012.11.017

Takahashi, N., Kuroda, H., Kuromori, T., Hirayama, T., Seki, M., Shinozaki, K., et al. (2004). Expression and interaction analysis of Arabidopsis Skp1-related genes. Plant Cell Physiol. 45, 83-91. doi: 10.1093/pcp/pch009

Tanaka, K., Nguyen, C. T., Liang, Y., Cao, Y., and Stacey, G. (2013). Role of LysM receptors in chitin-triggered plant innate immunity. Plant Signal. Behav. 8:e22598. doi: 10.4161/psb.22598

Thelin, L., Mutwil, M., Sommarin, M., and Persson, S. (2011). Diverging functions among calreticulin isoforms in higher plants. Plant Signal. Behav. 6, 905-910. doi: 10.4161/psb.6.6.15339

Thomma, B. P., Nurnberger, T., and Joosten, M. H. (2011). Of PAMPs and effectors: the blurred PTI-ETI dichotomy. Plant Cell 23, 4-15. doi: 10.1105/tpc.110. 082602

Tintor, N., and Saijo, Y. (2014). ER-mediated control for abundance, quality, and signaling of transmembrane immune receptors in plants. Front. Plant Sci. 5:65. doi: $10.3389 /$ fpls.2014.00065

Vaid, N., Macovei, A., and Tuteja, N. (2013). Knights in action: lectin receptor-like kinases in plant development and stress responses. Mol. Plant 6, 1405-1418. doi: $10.1093 / \mathrm{mp} / \mathrm{sst} 033$

Vaid, N., Pandey, P. K., and Tuteja, N. (2012). Genome-wide analysis of lectin receptor-like kinase family from Arabidopsis and rice. Plant Mol. Biol. 80, 365 388. doi: 10.1007/s11103-012-9952-8

Van Damme, E. J. M., Fouquaert, E., Lannoo, N., Vandenborre, G., Schouppe, D., and Peumans, W. J. (2011). "Novel concepts about the role of lectins in the plant cell," in The Molecular Immunology of Complex Carbohydrates-3, Vol. 705, ed. A. M. Wu (New York: Springer), 295-324.

Van Damme, E. J. M., Hao, Q., Chen, Y., Barre, A., Vandenbussche, F., Desmyter, S., et al. (2001). Ribosome-inactivating proteins: a family of plant proteins that do more than inactivate ribosomes. Crit. Rev. Plant Sci. 20, 395-465. doi: $10.1080 / 07352689.2001 .10131826$
Van Damme, E. J. M., Lannoo, N., and Peumans, W. J. (2008) Plant lectins. Adv. Bot. Res. 48, 107-209. doi: 10.1016/S0065-2296(08) 00403-5

Vandenborre, G., Groten, K., Smagghe, G., Lannoo, N., Baldwin, I. T., and Van Damme, E. J. M. (2010). Nicotiana tabacum agglutinin is active against Lepidopteran pest insects. J. Exp. Bot. 61, 1003-1014. doi: 10.1093/jxb/ $\operatorname{erp} 365$

Vandenborre, G., Smagghe, G., and Van Damme, E. J. M. (2011). Plant lectins as defense proteins against phytophagous insects. Phytochemistry 72, 1538-1550. doi: 10.1016/j.phytochem.2011.02.024

Vandenbussche, F., Desmyter, S., Ciani, M., Proost, P., Peumans, W. J., and Van Damme, E. J. M. (2004a). Analysis of the in planta antiviral activity of elderberry ribosome-inactivating proteins. Eur. J. Biochem. 271, 1508-1515. doi: 10.1111/j.1432-1033.2004.04059.x

Vandenbussche, F., Peumans, W. J., Desmyter, S., Proost, P., Ciani, M., and Van Damme, E. J. M. (2004b). The type-1 and type-2 ribosome-inactivating proteins from Iris confer transgenic tobacco plants local but not systemic protection against viruses. Planta 220, 211-221. doi: 10.1007/s00425-0041334-2

Van Hove, J., Fouquaert, E., Smith, D. F., Proost, P., and Van Damme, E. J. M. (2011). Lectin activity of the nucleocytoplasmic EUL protein from Arabidopsis thaliana. Biochem. Biophys. Res. Commun. 414, 101-105. doi: 10.1016/j.bbrc.2011.09.031

Wan, J., Tanaka, K., Zhang, X. C., Son, G. H., Brechenmacher, L., Nguyen, T. H., et al. (2012). LYK4, a lysine motif receptor-like kinase, is important for chitin signaling and plant innate immunity in Arabidopsis. Plant Physiol. 160, 396-406. doi: 10.1104/pp.112.201699

Wei, G. Q., Liu, R. S., Wang, Q., and Liu, W. Y. (2004). Toxicity of two type II ribosome-inactivating proteins (cinnamomin and ricin) to domestic silkworm larvae. Arch. Insect Biochem. Physiol. 57, 160-165. doi: 10.1002/arch.20024

Williams, C. E., Collier, C. C., Nemacheck, J. A., Liang, C., and Cambron, S. E. (2002). A lectin-like wheat gene responds systemically to attempted feeding by avirulent first-instar Hessian fly larvae. J. Chem. Ecol. 28, 1411-1428. doi: 10.1023/A:1016200619766

Williams, D. B. (2006). Beyond lectins: the calnexin/calreticulin chaperone system of the endoplasmic reticulum. J. Cell Sci. 119, 615-623. doi: 10.1242/ jcs.02856

Willmann, R., Lajunen, H. M., Erbs, G., Newman, M. A., Kolb, D., Tsuda, K., et al. (2011). Arabidopsis lysine-motif proteins LYM1 LYM3 CERK1 mediate bacterial peptidoglycan sensing and immunity to bacterial infection. Proc. Natl. Acad. Sci. U.S.A. 108, 19824-19829. doi: 10.1073/pnas.1112862108

Wirthmueller, L., Maqbool, A., and Banfield, M. J. (2013). On the front line: structural insights into plant-pathogen interactions. Nat. Rev. Microbiol. 11, 761-776. doi: $10.1038 /$ nrmicro3118

Wu, J., Luo, X., Guo, H., Xiao, J., and Tian, Y. (2006). Transgenic cotton, expressing Amaranthus caudatus agglutinin, confers enhanced resistance to aphids. Plant Breed.125, 390-394. doi: 10.1111/j.1439-0523.2006.01247.x

Xiang, Y., Song, M., Wei, Z., Tong, J., Zhang, L., Xiao, L., et al. (2011). A jacalinrelated lectin-like gene in wheat is a component of the plant defence system. $J$. Exp. Bot. 62, 5471-5483. doi: 10.1093/jxb/err226

Xin, Y., Xiangrong, Z., Mingju, Z., Wenchao, G., Yingchuan, T., Qizhong, X., et al. (2011). Transgenic potato overexpressing the Amaranthus caudatus agglutinin gene to confer aphid resistance. Crop Sci. 51, 2119-2124. doi: 10.2135/cropsci2010.11.0650

Yamaji, Y., Maejima, K., Ozeki, J., Komatsu, K., Shiraishi, T., Okano, Y., et al. (2012). Lectin-mediated resistance impairs plant virus infection at the cellular level. Plant Cell 24, 778-793. doi: 10.1105/tpc.111.093658

Yong, W. D., Xu, Y. Y., Xu, W. Z., Wang, X., Li, N., Wu, J. S., et al. (2003). Vernalizationinduced flowering in wheat is mediated by a lectin-like gene VER2. Planta 217 261-270.

Zhang, C., Shi, H., Chen, L., Wang, X., Lu, B., Zhang, S., et al. (2011). Harpin-induced expression and transgenic overexpression of the phloem protein gene AtPP2-A1 in Arabidopsis repress phloem feeding of the green peach aphid Myzus persicae. BMC Plant Biol. 11:11. doi: 10.1186/14712229-11-11

Zipfel, C., Kunze, G., Chinchilla, D., Caniard, A., Jones, J. D., Boller, T., et al. (2006). Perception of the bacterial PAMP EF-Tu by the receptor EFR restricts Agrobacterium-mediated transformation. Cell 125, 749-760. doi: 10.1016/j.cell.2006.03.037 
Zhang, W., Peumans, W. J., Barre, A., Astoul, C. H., Rovira, P., Rougé, P., et al. (2000). Isolation and characterization of a jacalin-related mannose-binding lectin from salt-stressed rice (Oryza sativa) plants. Planta 210, 970-978. doi: $10.1007 / \mathrm{s} 004250050705$

Conflict of Interest Statement: The authors declare that the research was conducted in the absence of any commercial or financial relationships that could be construed as a potential conflict of interest.

Received: 30 June 2014; accepted: 25 July 2014; published online: 13 August 2014.
Citation: Lannoo N and Van Damme EJM (2014) Lectin domains at the frontiers of plant defense. Front. Plant Sci. 5:397. doi: 10.3389/fpls.2014.00397

This article was submitted to Plant Physiology, a section of the journal Frontiers in Plant Science.

Copyright (c) 2014 Lannoo and Van Damme. This is an open-access article distributed under the terms of the Creative Commons Attribution License (CC BY). The use, distribution or reproduction in other forums is permitted, provided the original author(s) or licensor are credited and that the original publication in this journal is cited, in accordance with accepted academic practice. No use, distribution or reproduction is permitted which does not comply with these terms. 